بناء مقياس التفاؤل الدراسي لطلبة كلية التربية الرياضية في جامعة الموصل وعلاقته بالتحصيل الاراسي

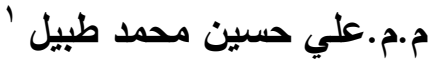

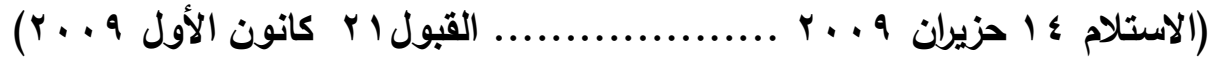

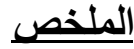

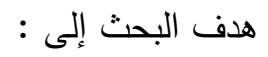

- بناء مقياس التفاؤل الدراسي لطلبة كلية التربية الرياضية في جامعة الموصل .

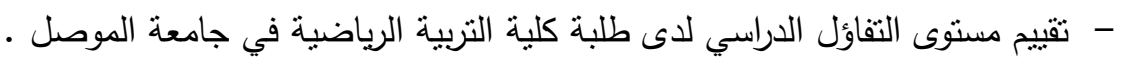

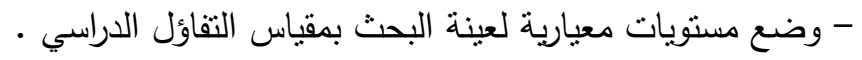

- التعرف إلى العلاقة بين مستوى التفاؤل الدراسي ومعدل التحصيل الدراسي لطلبة كلية التربية الرياضية في جامعة الموصل.

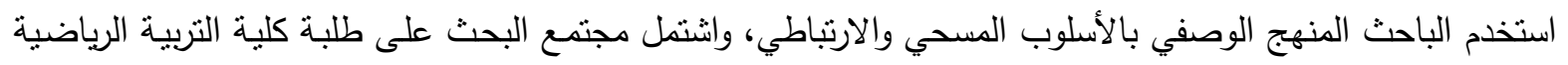

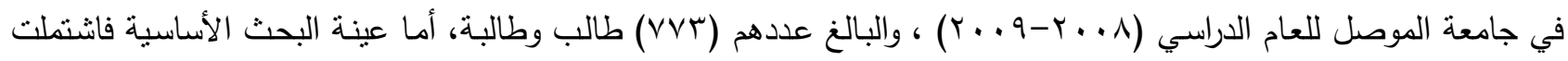

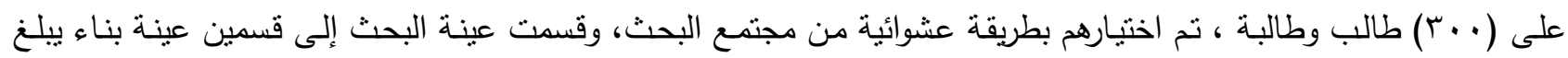

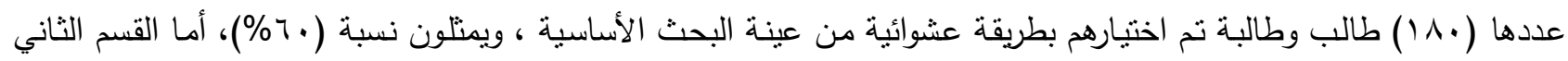

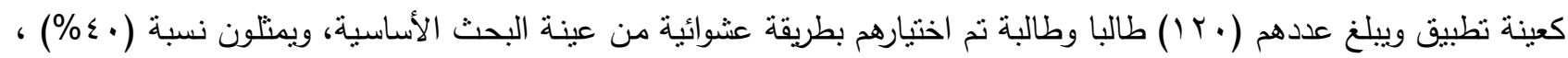
واشتملت أداة البحث على مقياس التفاؤل الدراسي الذي أعده الباحث باعتماد الخطوات والإجراءات العلميـة في بناء المقاييس، والمتضمنة بصدق الخبراء، والتحليل الإحصائي للفقرات بأسلوبي (المجموعتين المنطرفتني، والاتساق الداخلي) ، وتم التأكد من

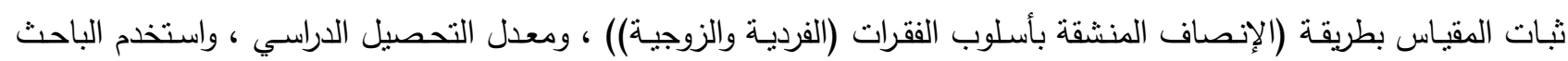

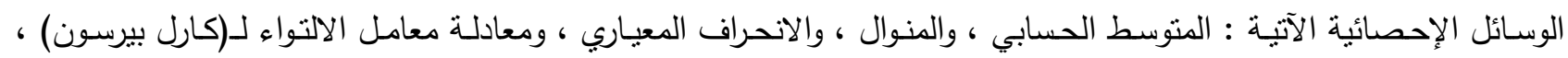

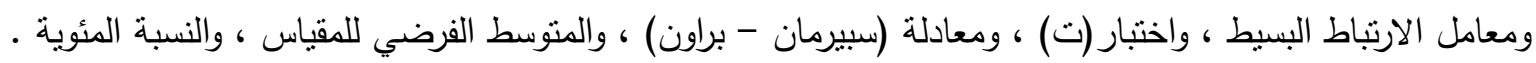
وقد نوصل الباحث إلى الاسنتتاجات الآتية :

- فاعلية المقياس الذي تم بنائه لقياس مستوى التفاؤل الدراسي لطلبة كلية التربية الرياضية في جامعة الموصل .

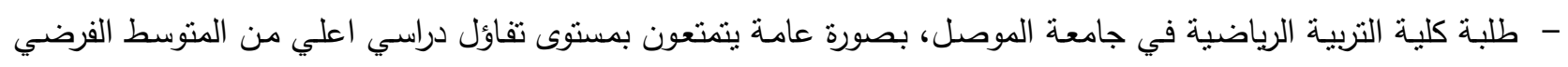
للمقياس، وهذا يدل على تمتعهم بمستوى تفاؤل جيد مما يؤثر إيجابا على نوافقهم وتحصيلهم الدراسي، من حيث الدافعية للاراسة

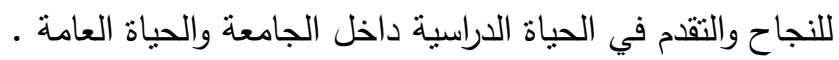
- نم وضع مستويات معيارية لعينة البحث في مقياس التفاؤل الدراسي .

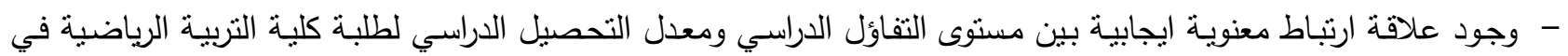

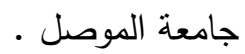

\section{Constructing an optimism scale for the students of physical education college in the University of Mosul and it is relation with academic achievement}




\section{Asst. Lecturer: Ali Hussein Mohammed}

\section{ABSTRACT}

Aims of study:

Constructing an optimism scale for the students of physical education college in the University of Mosul.

Evaluating the level of optimism of the students of physical education college in the University of Mosul.

Setting standard levels for the sample of study in the optimism scale.

Recognizing the relation between the level of optimism and the average of academic achievements of the students of physical education in the University of Mosul.

The researcher used the descriptive approach by survey and correlation style. The society of study included (773) students from the college of physical education in University of Mosul (2008-2009). The essential sample of study included (300) students chosen randomly from the society of study. The sample of study was divided into two divisions: sample of structure which included (180) students, i.e., (60\%), chosen randomly from the essential sample of study, and sample of application which included (120) students, i.e., (40\%), chosen randomly from the essential sample of study. The instrument of study included the scale of optimism that the research Constructed by taking scientific measures and steps in Constructed the scales. The steps and measures included validity of experts, statistical analysis of items by ways of (extreme groups and internal consistency). Scale stability has been verified by using the way of splet halves single and dual items manner, and average of academic achievement. Also, the researcher used the following statistical analysis: arithmetic mean, standard deviation, Carl Person Factor Equation, factor of simple correlation, T-test, SpearmanBrown Equation, assumption average of scale and percentage.

Conclusions:

- Efficiency of Constructed scale for evaluating the level of optimism for the students of college of physical education in the university of Mosul.

- Students of college of physical education in the university of Mosul, in general, have a level of optimism higher than assumption average of scale. This refers that they have good level of optimism which affect positively on their consistence and academic achievement, namely, they are enthusiastic for success and advancement in the study in the university as well as in their life (in general).

- standard levels have been set for the sample of study in the optimism scale.

- There positive significant correlations between the level of optimism and the average of academic achievement of the students of physical education college in the university of Mosul.

$$
\text { 1-التعريف بالبحث : المقدمة وأهميث البحث : }
$$

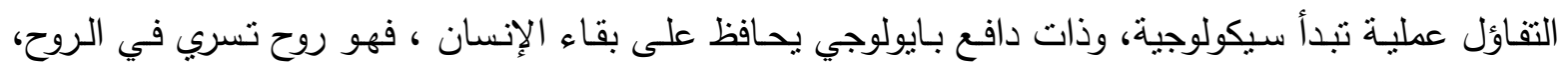

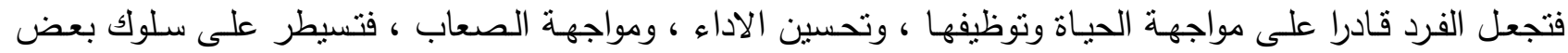

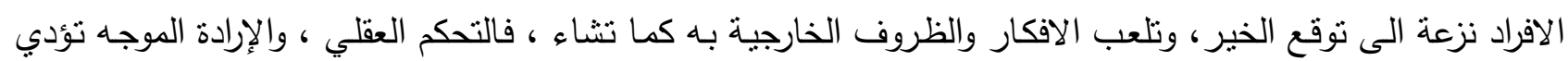

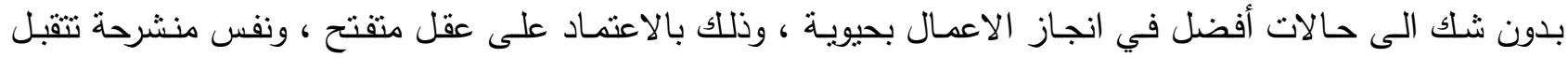

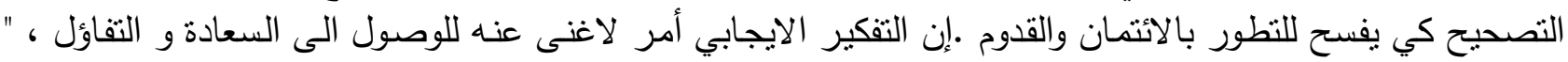

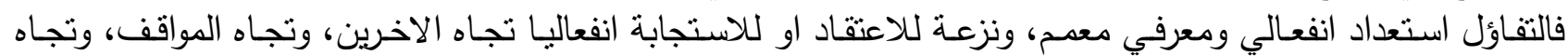

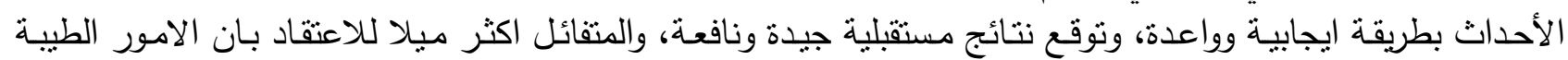

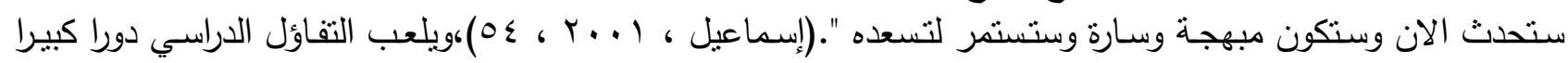

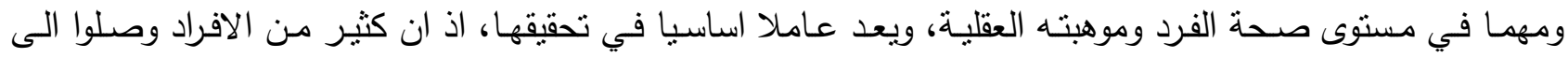

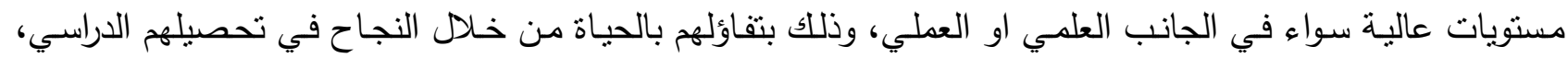




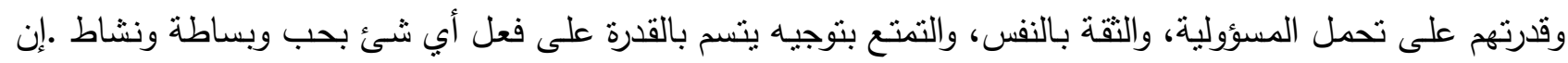

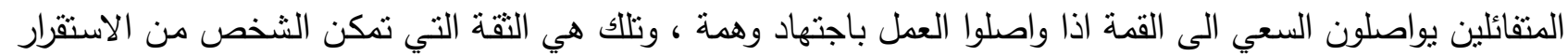

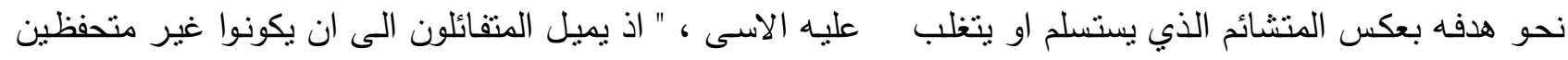

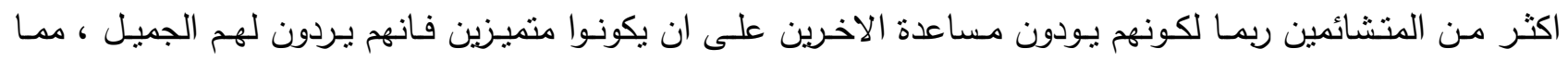

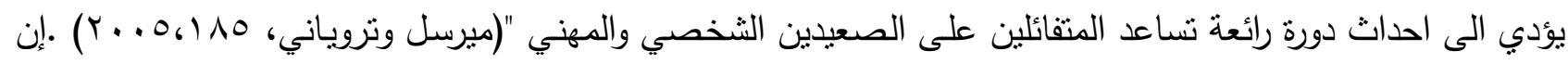

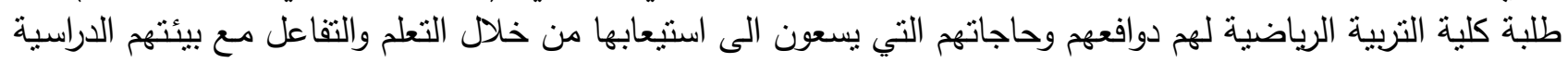

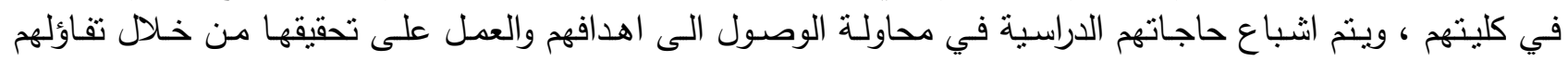

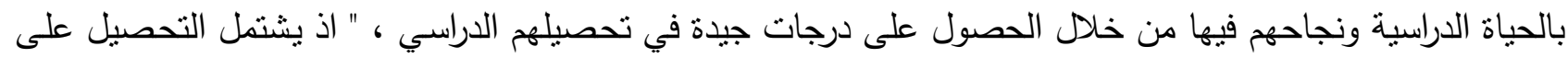

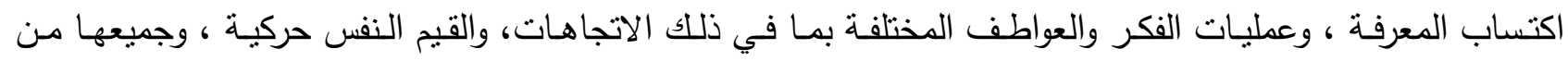

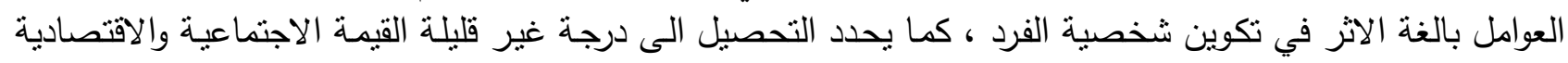

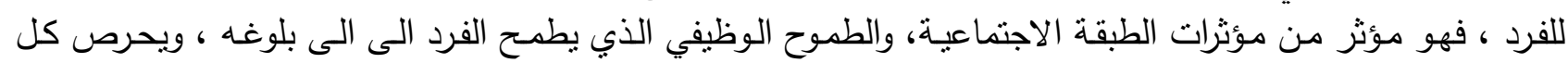

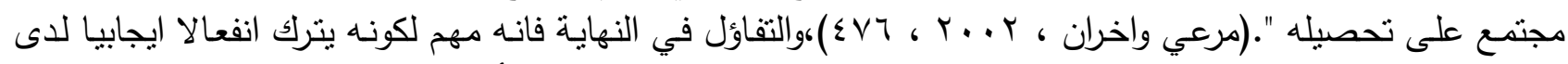

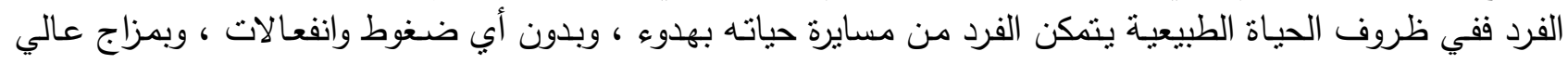

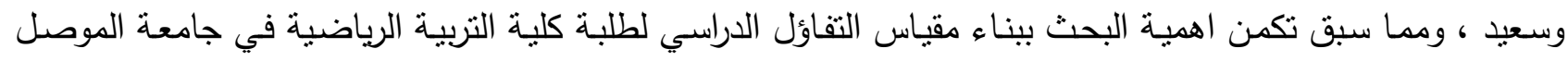

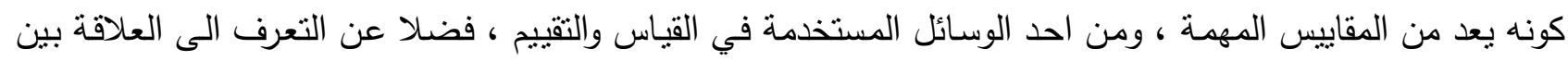

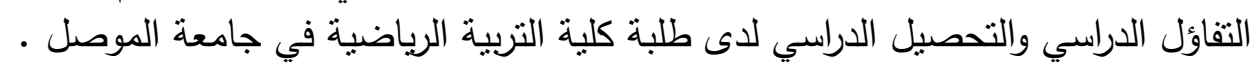

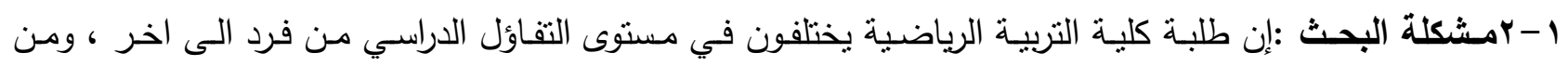
المعروف ان الطلبة يتفاوتون في حاجاتهم واتجاهاتهم ودرجة ميولهم نحو دراستهم ، لذلك فان التعرف الى مستوى التفاؤل

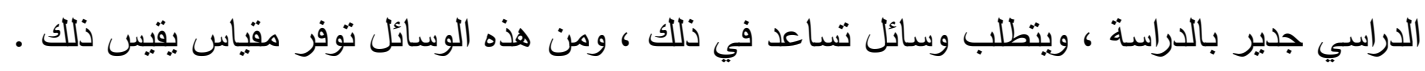

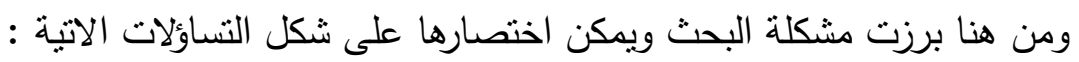

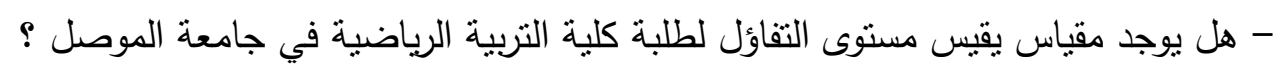
- ما هو مستوى التفاؤل الدراسي لدى طلبة كلية التربية الرياضية في جامعة الموصلة فلئل

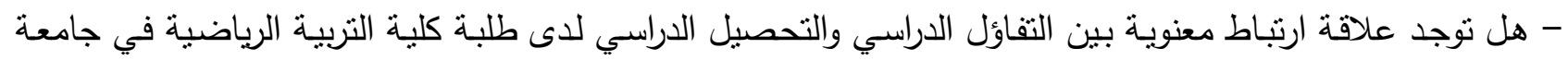
الموصل؟ هون توجن

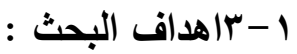

1-r-1 بناء مقياس التفاؤل الدراسي لطلبة كلية التربية الرياضية في جامعة الموصل .

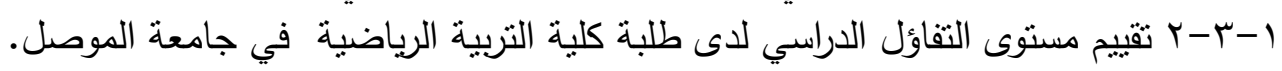
ا

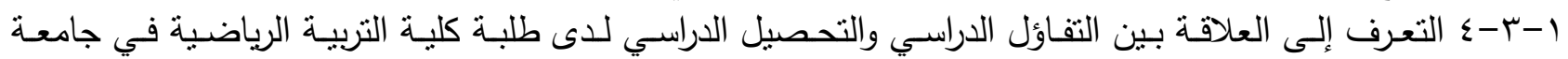
الموصل . الم:

: 1

ا- - - اتوجد علاقة ارتباط معنوية ايجابية بين التفاؤل الدراسي والتحصيل الدراسي لدى طلبة كلية التربية الرياضية في

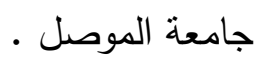

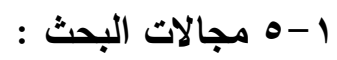

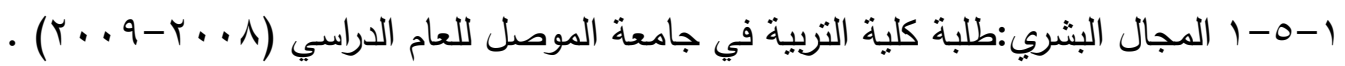

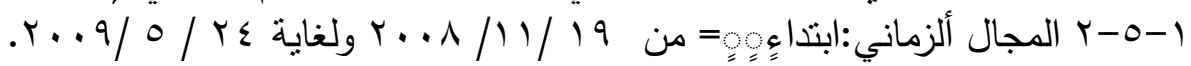

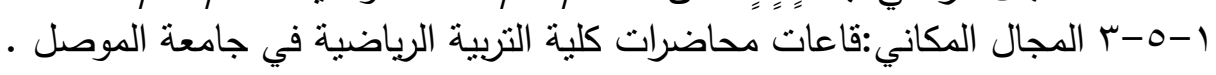

1- 1- اتحديد المصطلحات:

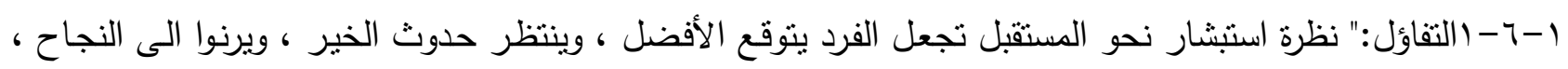

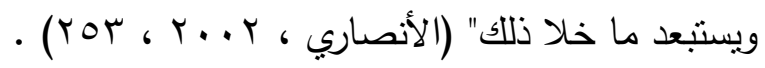

iv. 


\section{بناء مقياس التفاول الدراسي لطابة كلية التربية الرياضية في جامعة الموصل وعلاقته بالتمصيل الدراسي}

وعرف الباحث التفاؤل الدراسـي إجرائيا بانه:" الدرجة الكلية التي يحصل عليها طلبة كلية التربية الرياضية في جامعـة

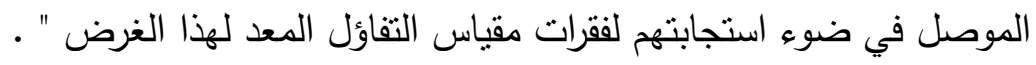

1-1-rالتحصيل الدراسي:هو" مدى استيعاب الطالب لبعض جوانب التعلم المتضمن في المادة الدراسية ، ويستخل عليه

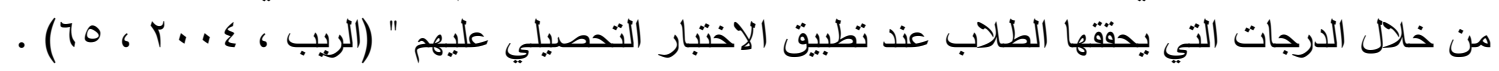

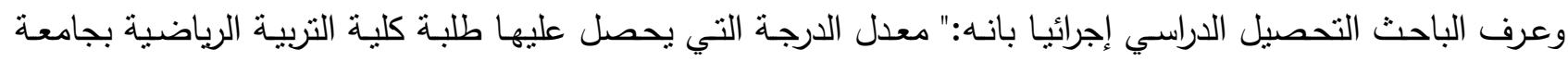

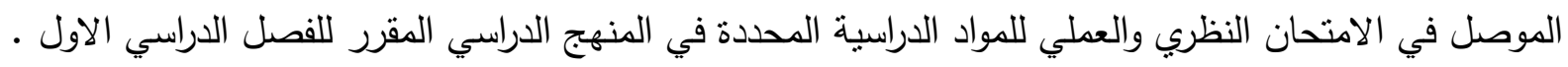

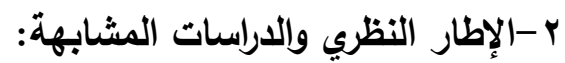 \\ r - ب الإطار النظري:}

ץ- - - امفهوم التفاؤل: يعد موضوع التفاؤل من المواضيع المهمة، وذا فاعلية كبيرة في ديمومة حياة الافراد واستمرارها بالشكل الذي يضمن تحقيق نجاحها، وان السلوك البشري ككل ينظم بالميل لخفض الاستثارة الناتجة عن التوترات غير

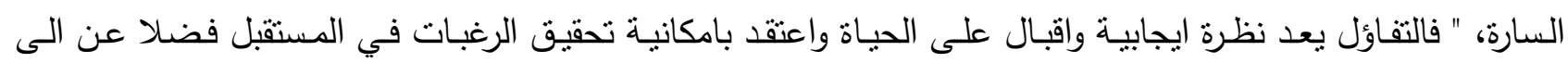

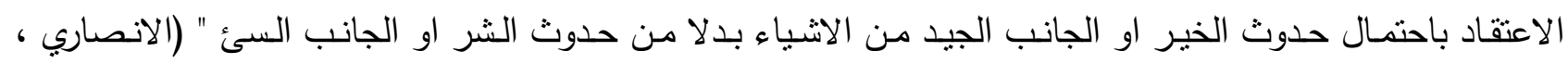

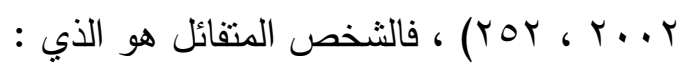

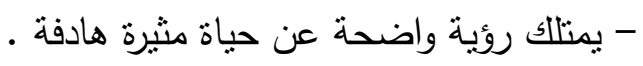

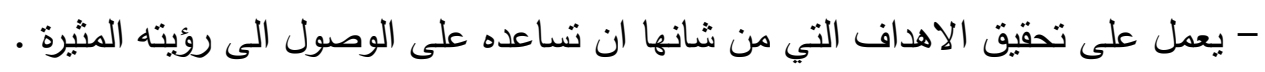

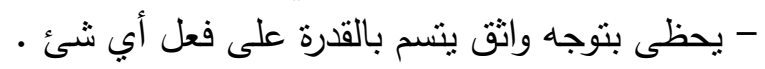

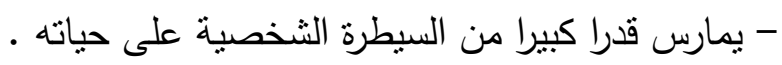

- يتحمل مستويات عالية من المسئولية الثخصية.

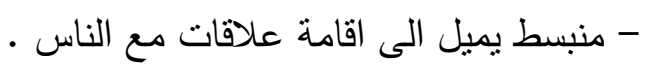

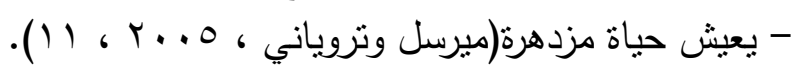

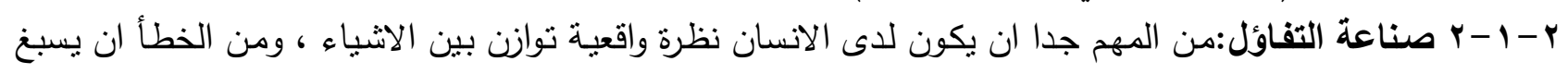

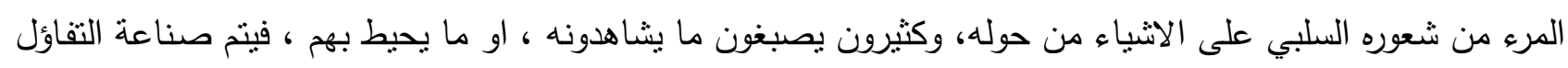

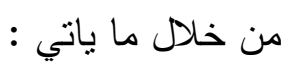

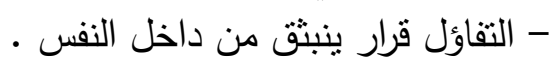
- المظهر والثكل الموحي بالثقة في المشي والحركة والالتفات والقعود والنظر والكلام والمشاركة مهر .

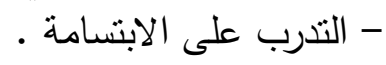

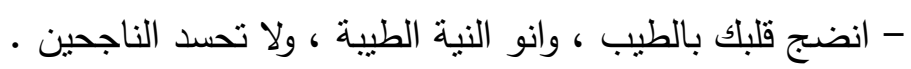

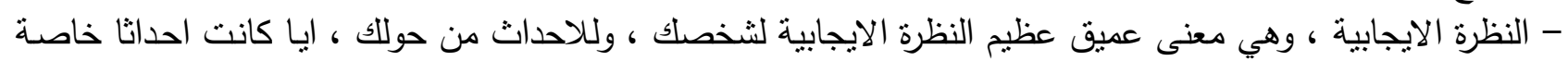

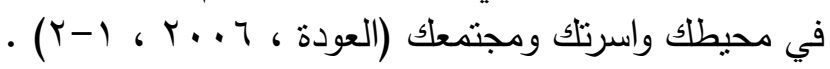

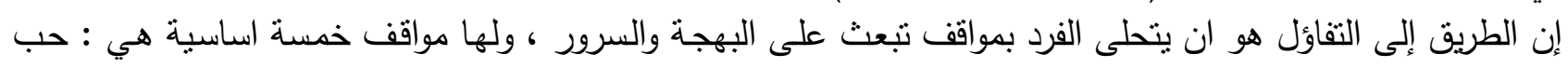

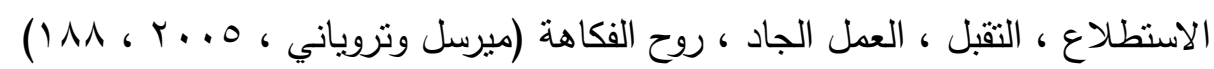

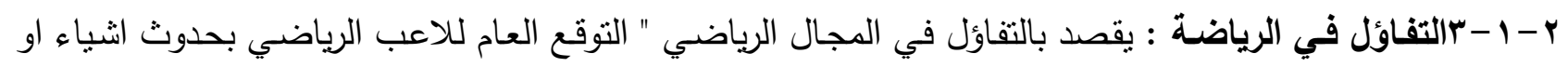

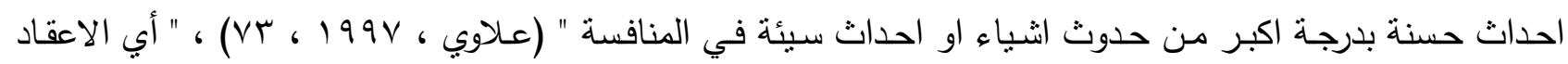

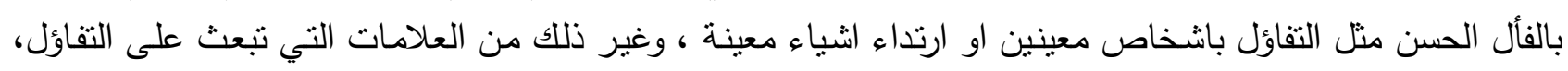

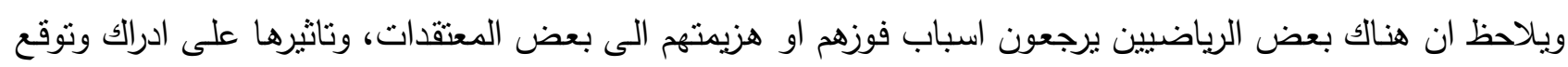

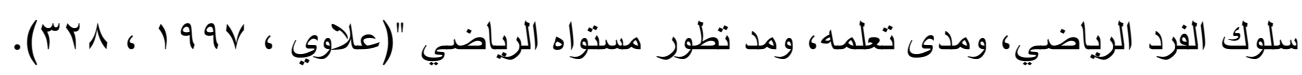
r- 
إن التفاؤل بصفة عامـة يؤدي بالقدرة الى الصحة الجيدة ومقاومة المرض، وكثيرا ما تكون الثخصية المتفائلة

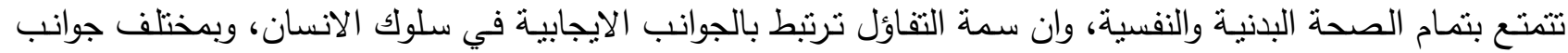

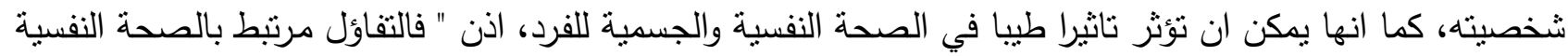
والصحة الجسمية، وهذا ما اكدته دراسة (ثاير وكارفر) التي افترضت ان التفكير الايجابي، والنزعة التفاؤلية نحو الحياة

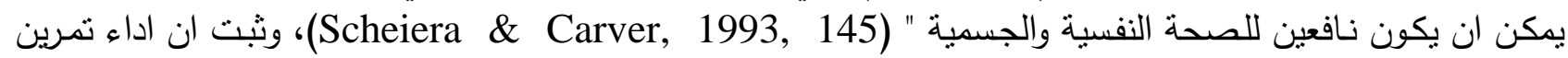

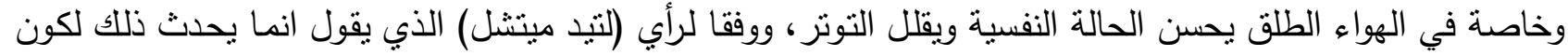

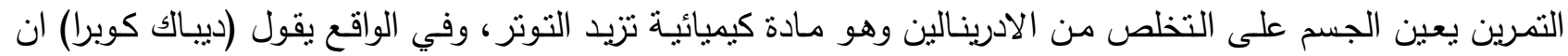

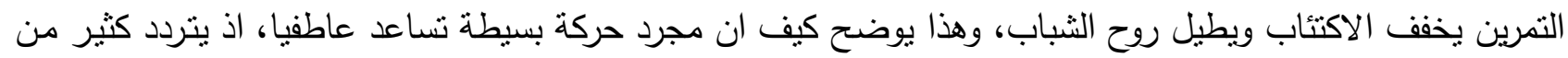

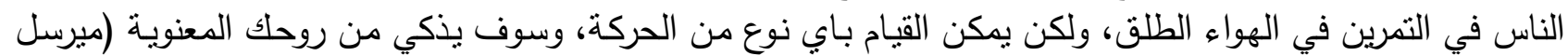

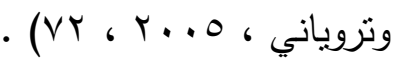

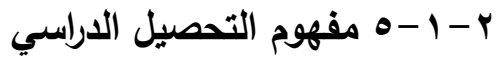

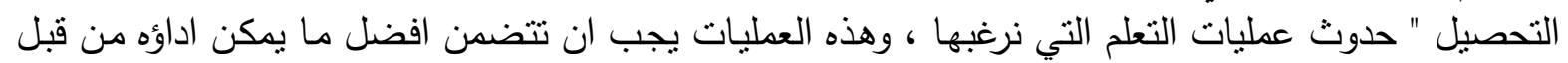

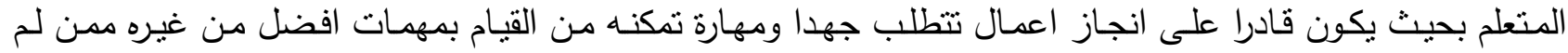

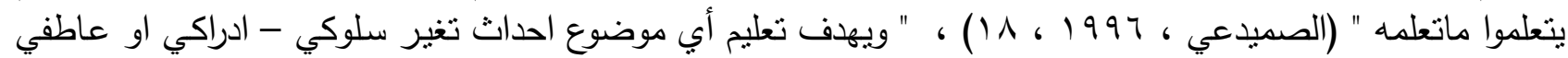

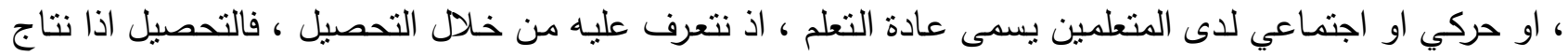

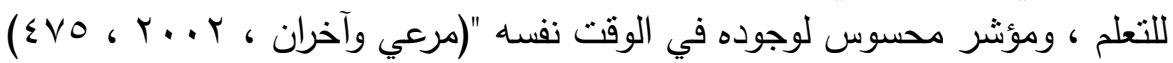

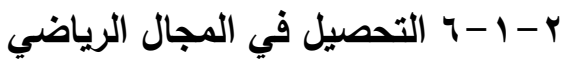

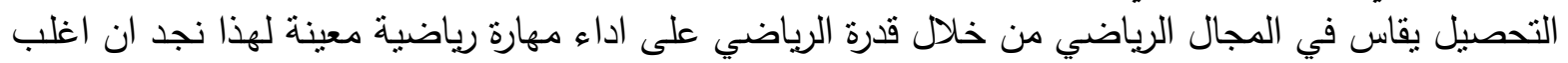

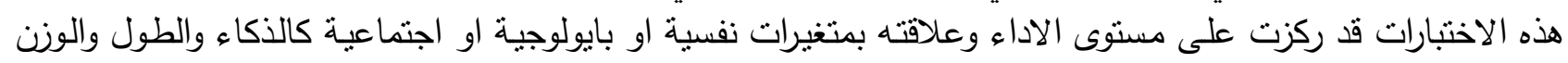

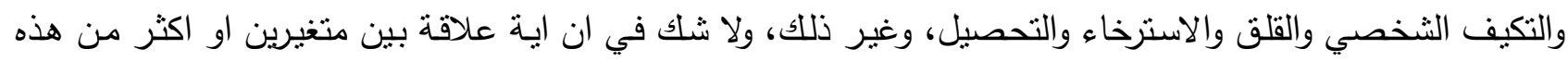

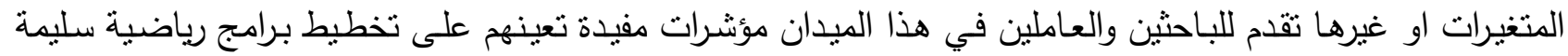

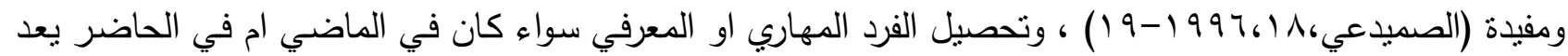

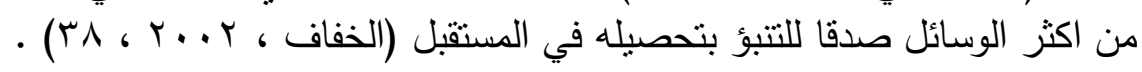

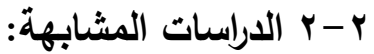

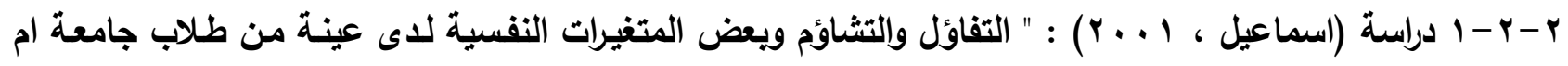
القرى " (

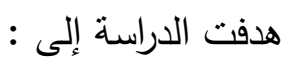

- التعرف على مقدار واتجاه العلاقة بين التفاؤل والتشاؤم وكل من الشعور بالوحدة النفسية ، وقلق المـوت ، ووجهة

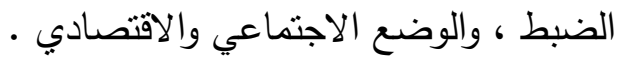

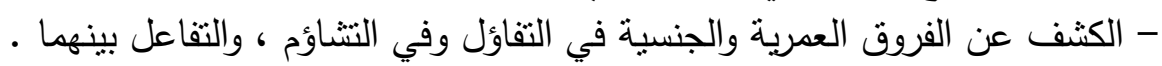

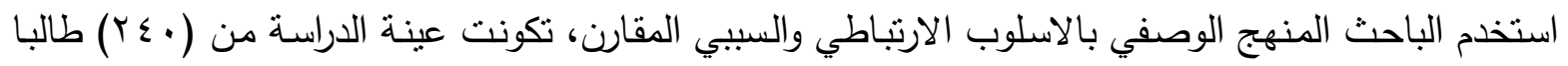

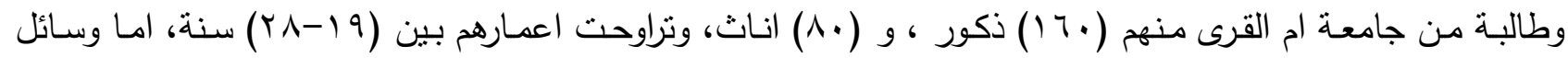

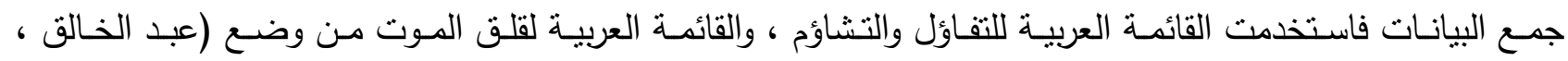

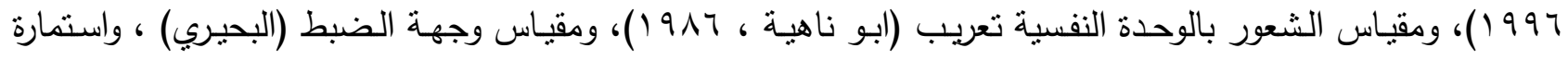

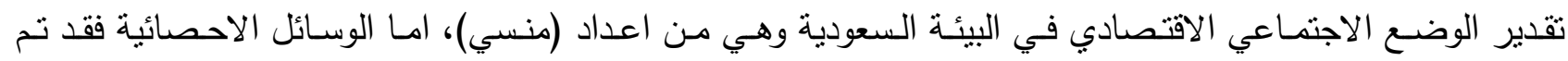

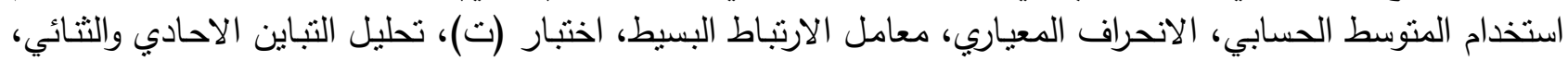

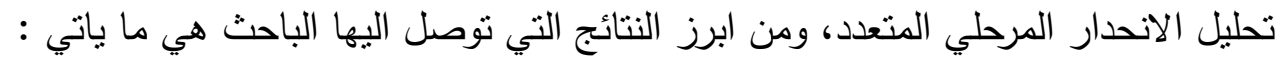

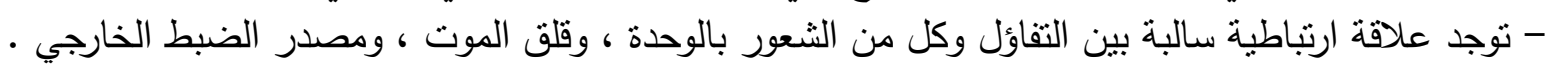

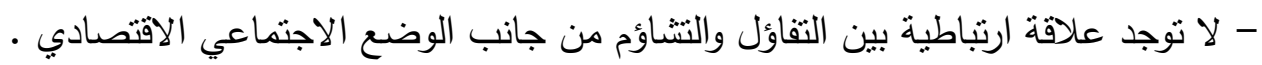

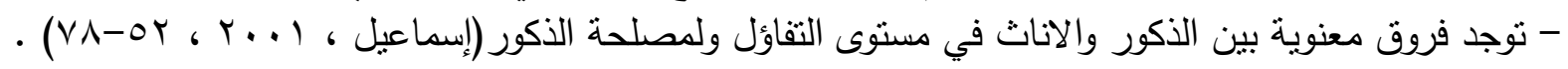

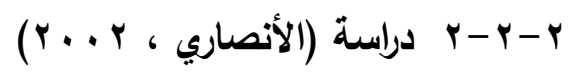


" قياس التفاؤل والتشاؤم وعلاقتهما ببعض المتغيرات الثخصية لدى طلاب جامعة الكويت "

$$
\text { هدف البحث إلى : }
$$

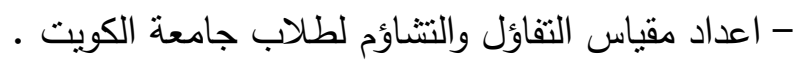

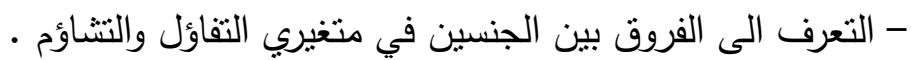

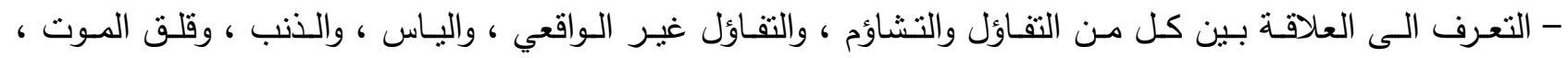

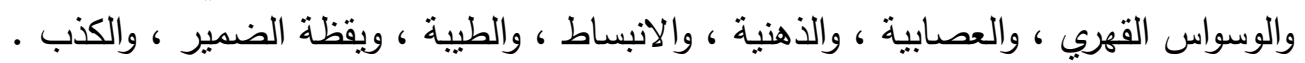

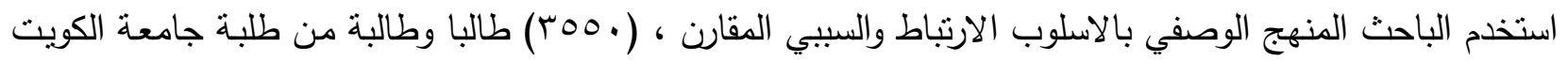

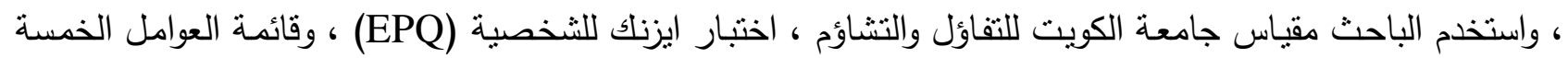

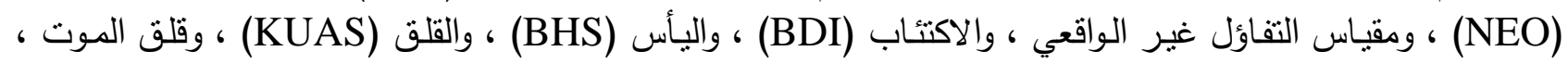

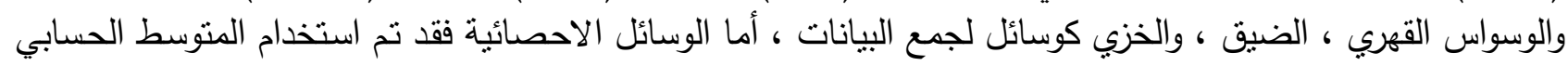

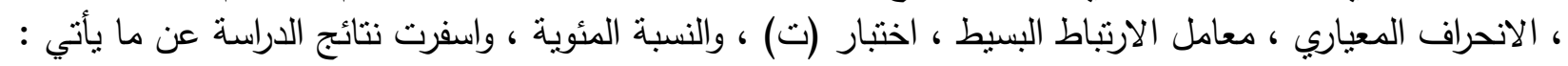

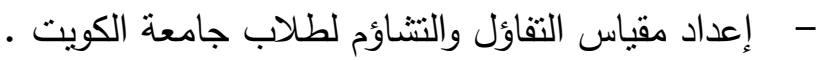

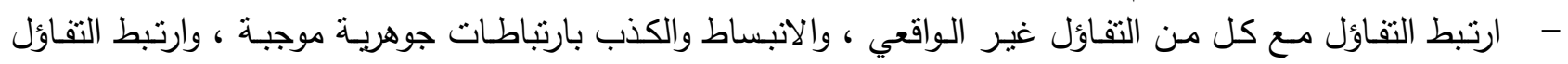

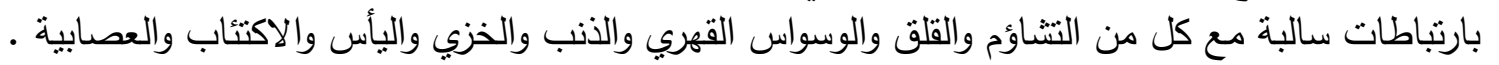

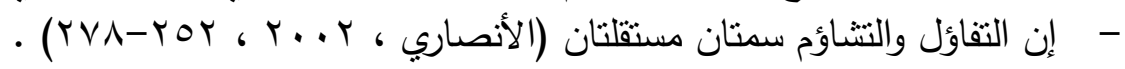

$$
\text { r- r-إجراءات البحث : }
$$

استخدم الباحث المنهج الوصفي بالأسلوب المسحي والارتباط لملاءمته وطبيعة البحث

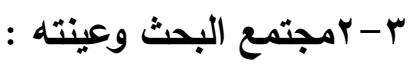

$$
\begin{aligned}
& \text { r-r - امجتمع البحث المئ }
\end{aligned}
$$

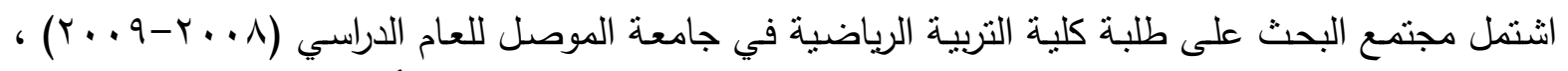

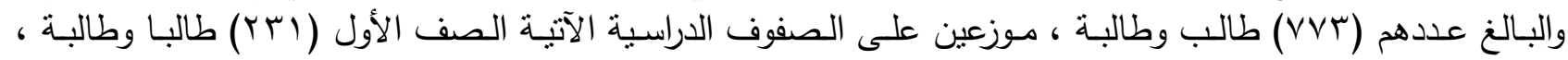

\begin{tabular}{|c|c|c|c|c|c|}
\hline \multirow{2}{*}{ النسبة المئوية } & \multirow{2}{*}{ المجتمع الكلي } & \multicolumn{2}{|c|}{ عدد الطلبة } & \multirow{2}{*}{ الصفوف } & \multirow{2}{*}{ ت } \\
\hline & & إناث & ذكور & & \\
\hline$\% r$. & rrI & $r q$ & $r \cdot r$ & طلبة الصف الأول & 1 \\
\hline$\% r^{q}$ & YrY & 7 & Y19 & طلبة الصف الثاني & $r$ \\
\hline$\%$ \%r & $I \vee \wedge$ & 19 & 194 & طلبة الصف الثالث & $r$ \\
\hline$\% \backslash \wedge$ & $1 \leq Y$ & 7 & 149 & طلبة الصف الرابع & $\varepsilon$ \\
\hline$\% 1 \ldots$ & VVr & $\Delta V$ & V19 & المجموع الكلي & \\
\hline
\end{tabular}

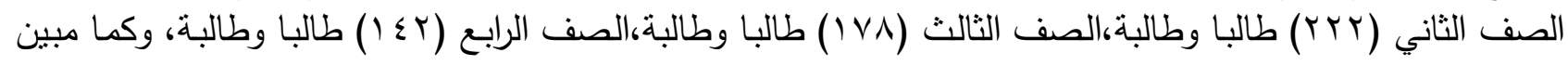

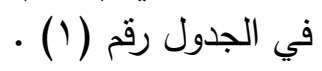

الجدول رقم (1) ايبين تفاصيل مجتمع البحث

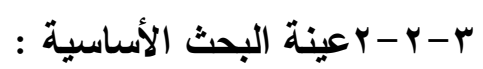

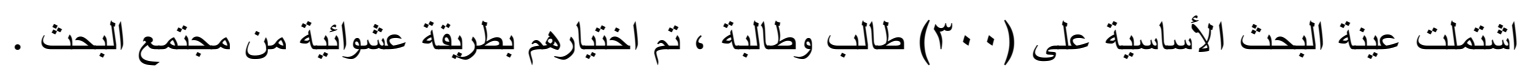

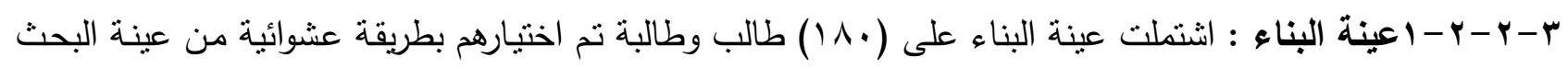
الأساسية ، ويمتلون نسبة ( • \%\%) ، منهم (10 ) طالب وطالبـة كعينة تمبيز أي صدق البناء (التحليل الإحصائي

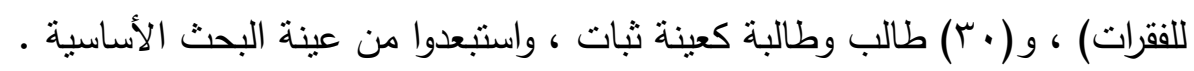




\section{: r r-r-r r-r}

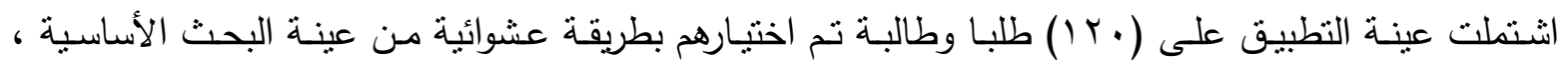

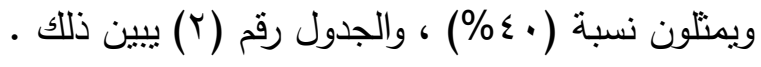

الجدول رقم (r)ييين تفاصيل عينة البناء والنطبيق

\begin{tabular}{|c|c|c|c|c|c|}
\hline \multirow{2}{*}{ العلي } & \multirow{2}{*}{ التطبيقة } & \multirow{2}{*}{ عينة البناء } & \multicolumn{2}{|c|}{ عينة البناء } & \multirow{2}{*}{ العينات } \\
\hline & & & عينة الثبات & عينة التمييز & \\
\hline$\mu \ldots$ & ir. & 11. & $\mu$. & 10. & طلبة كلية التربية الرياضية \\
\hline$\% 1 \ldots$ & $\%$ \% . & $\% 4$. & $\% \backslash V$ & $\% \wedge r$ & النسبة المئوية من عينة البحث \\
\hline
\end{tabular}

r-r أداة البحث : نظرا لعدم وجود مقياس لقياس مستوى التفاؤل لطلبة كلية التربية الرياضية في جامعة الموصل ، قام الباحث بيناء هذا المقياس ليتلاعم ومجتمع البحث الحالي .

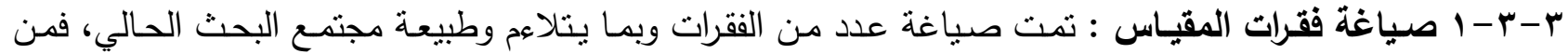

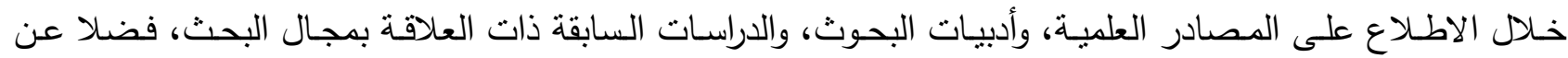

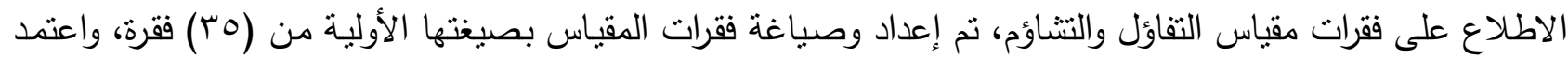
الباحث في إعداد الفقرات وصياغتها على أسلوب (ليكرت) المطور ، وهو شبيهة بأسلوب الاختيار من متعدد، إذ يقدم للمستجيب فقرات ويطلب منه تحديد إجابته باختيار بديل واحد من بين عدة بدائل لها أوزان مختلفة . r-r-r

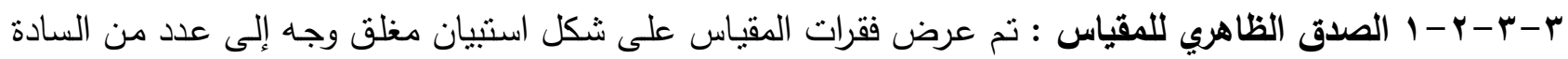
ذوي الخبرة والاختصاص* في مجال العلوم التربوية والنفسية، ومجال القياس والتقويم، اذ يعد هذا الإجراء وسيلة مناسبة مئية

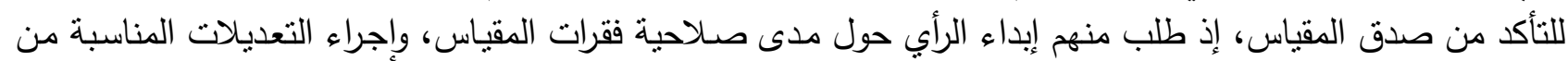

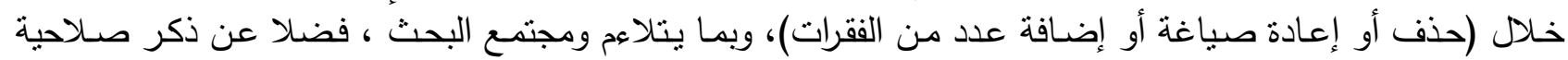

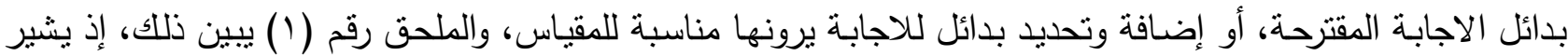

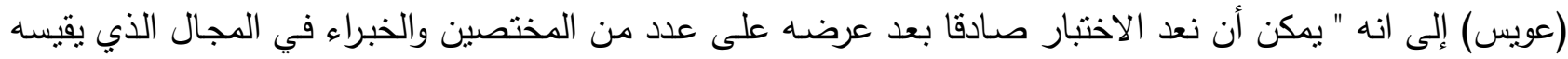

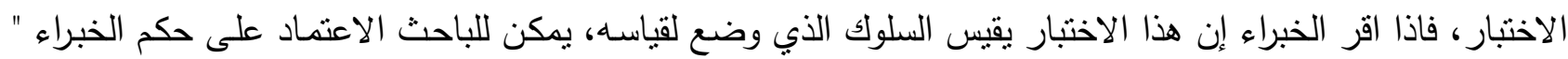

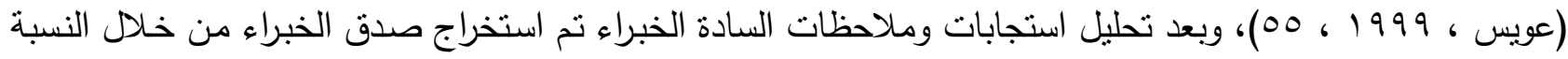

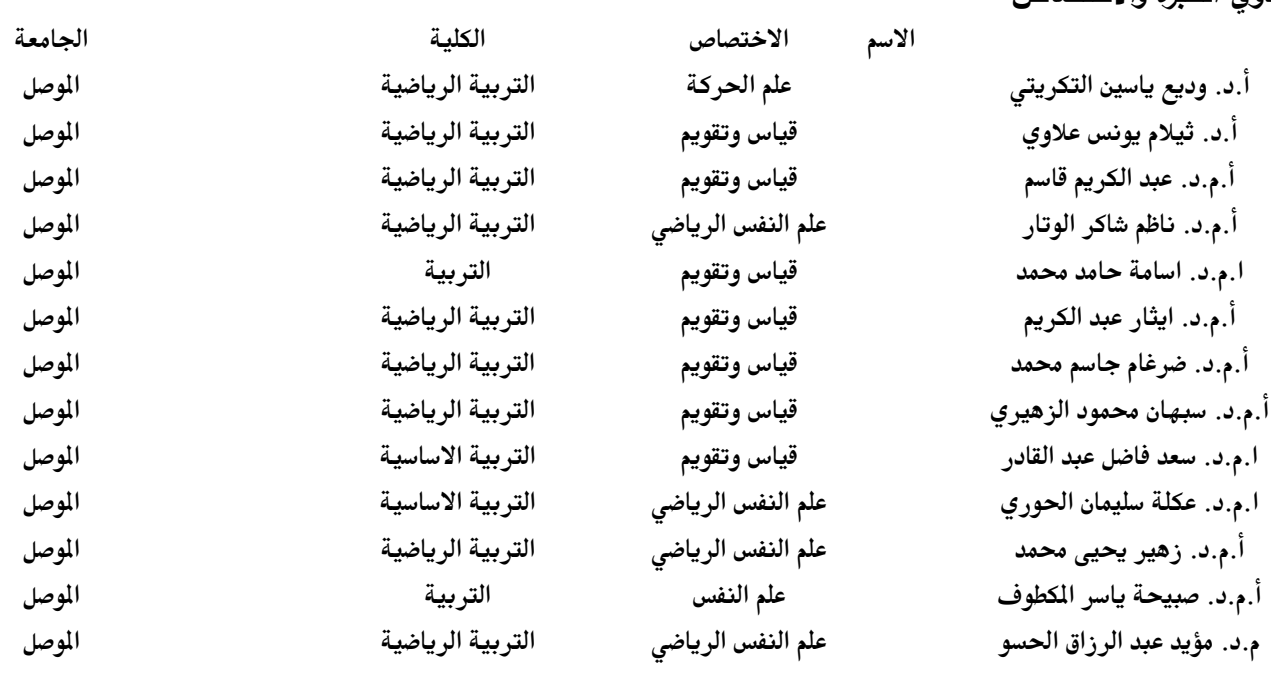




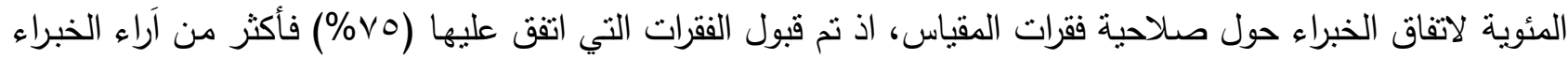

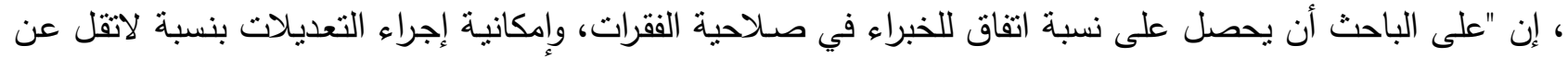

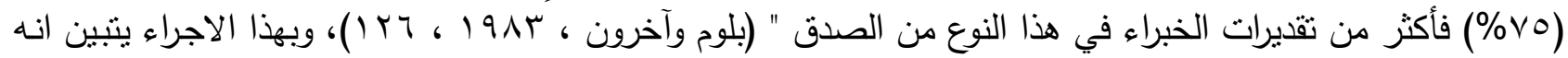

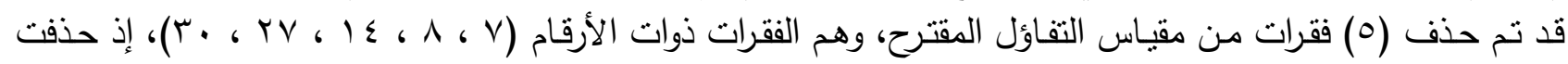

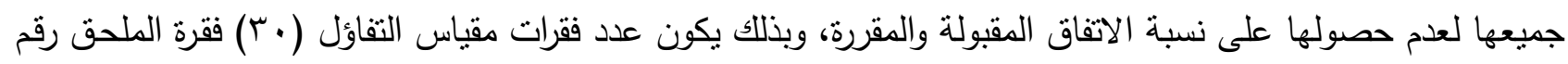
(Y) تم الاعتماد عليها في عملية إجراء صدق التمبية التمافيز (التحليل الإحصائي للفقرات). r-r-r-r-r-r-r-r r-r-r-r - 1 - اسلوب المجموعتين المتطرفتين

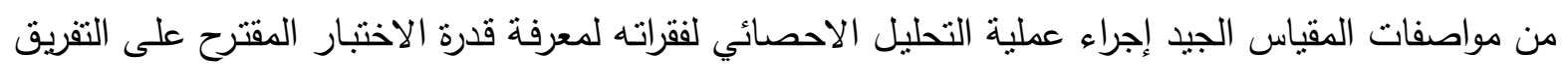

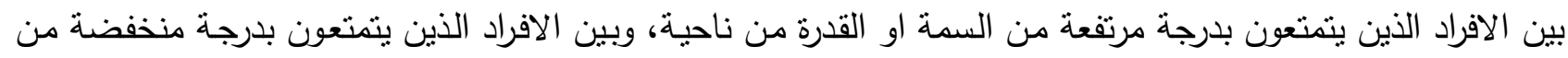

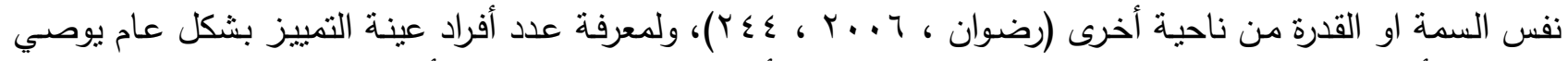

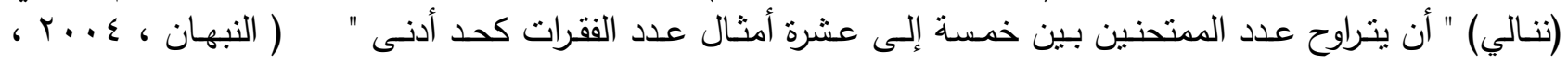

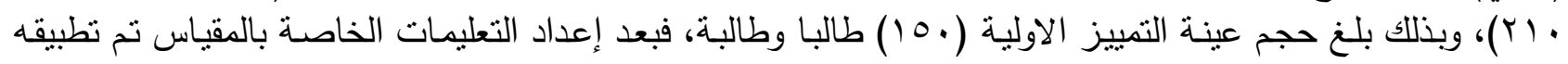

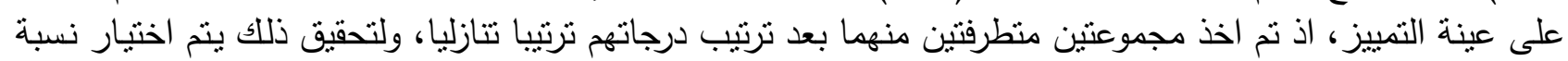

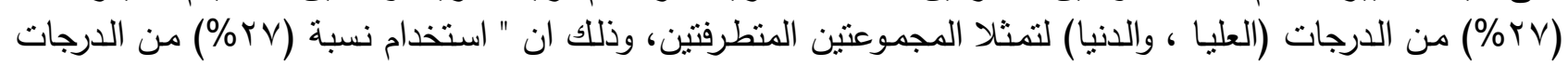

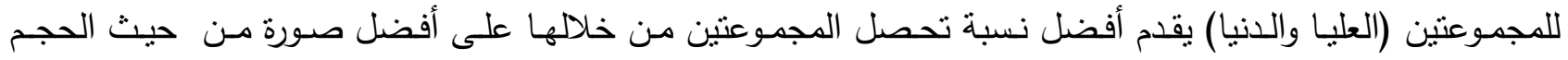

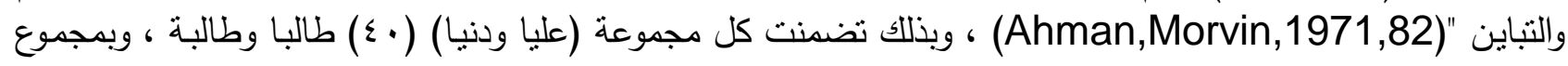

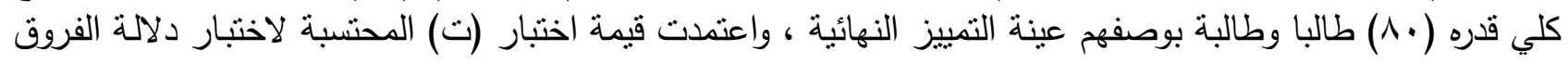

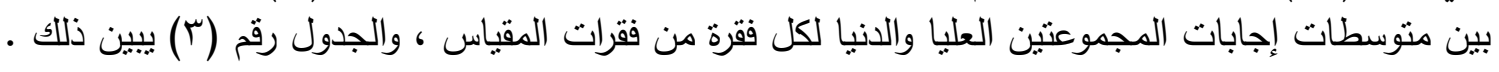

الجدول رقم (r) يبين نتائج الاختبار التائي لحساب التمييز لفقرات مقياس التفاؤل الاراسي

\begin{tabular}{|c|c|c|c|c|c|c|c|c|}
\hline الفروق & معامل التمييز & رقف & دلالة الفروق & معامل & رقم & الفروق دلالة & التمييز & رقام \\
\hline مغنوي & $r, \cdot r$ &.$M 1$ & معنوي & Y,TVY & .11 & معنوي & $r, .0 \wedge$ & .1 \\
\hline مغنوي & $r, \varepsilon r r$ &.$M Y$ & معنوي & $r, \wedge \circ \varepsilon$ & $.1 r$ & معنوي & $r, \leqslant r 1$ &.$r$ \\
\hline غير معنوي & $\cdot, 7 \wedge 1$ &.$M T$ & معنوي & $Y, Y \leq$ & $.1 \%$ & معنوي & $r, \cdot \leq r$ &.$r$ \\
\hline معنوي & $r, q . \varepsilon$ &.$Y \varepsilon$ & معنوي & $r, r \leq \varepsilon$ & $.1 \leq$ & معنوي & $1, \wedge \leq \varepsilon$ &.$\varepsilon$ \\
\hline معنوي & $r, \Lambda, \theta$ & .40 & معنوي & $Y, 011$ & .10 & معنوي & $1,91$. & .0 \\
\hline معنوي & $r, 07 r$ &.$Y 7$ & معنوي & $1, \vee 9 \varepsilon$ & .17 & معنوي & r,rTV & .7 \\
\hline معنوي & $r, \ldots r$ & $r V$ & غير معنوي & $1, Y r$ & $.1 \mathrm{~V}$ & معنوي & $1, V 7 V$ &.$V$ \\
\hline معنوي & r,rrr & $r \wedge$ & معنوي & $r, q \circ q$ & .11 & غير معنوي & $\cdot, \vee \vee V r$ &.$\wedge$ \\
\hline غير معنوي & $\cdot, v \cdot V$ & .49 & غير معنوي &., 978 & .19 & معنوي & $r, r r q$ & .9 \\
\hline معنوي & $r, I Y r$ &.$r$. & غير معنوي & צ &.$r$. & معنوي & Y,qYI & .1. \\
\hline
\end{tabular}

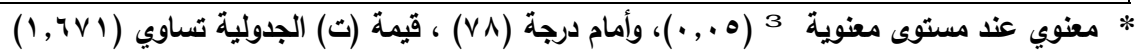

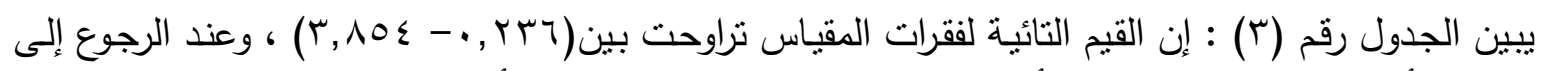

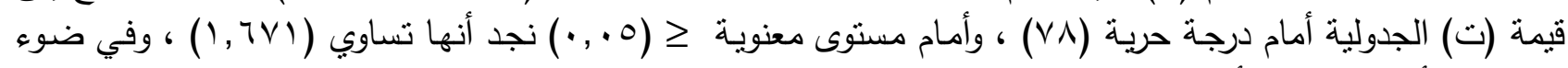

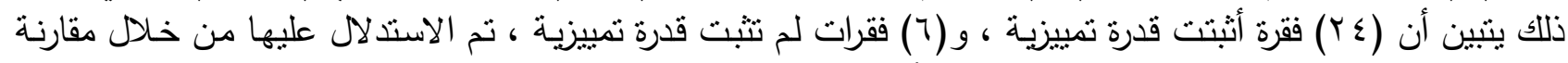

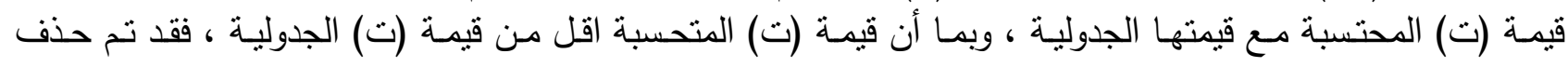
الفقرات ضعيفة التمييز

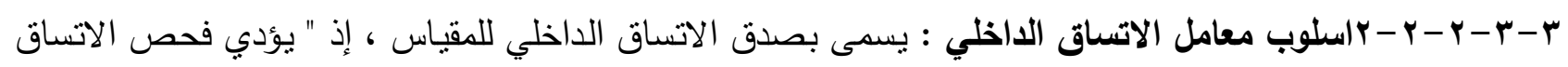

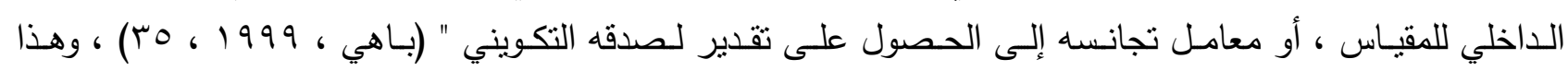




\section{بناء مقياس التفاول الدراسي لطابة كلية التربية الرياضية في جامعة الموصل وعلاقته بالتصصيل الدراسي}

الأسلوب " يقدم لنا مقياسا متجانسا في فقراته بحيث تقيس كل فقرة البعد السلوكي نفسه الذي يقيسه المقياس ككل ، فضلا

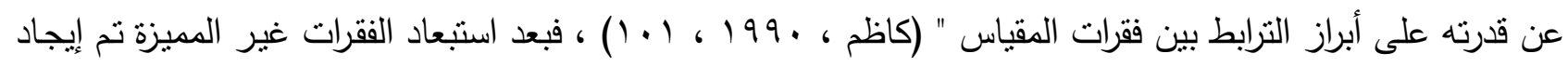
معامل ارتباط درجة كل فقرة بالدرجة الكلية للمقياس لنفس عينة التمييز البالغة ( •ـ) طالب وطالبة ، وقد تم استخدام

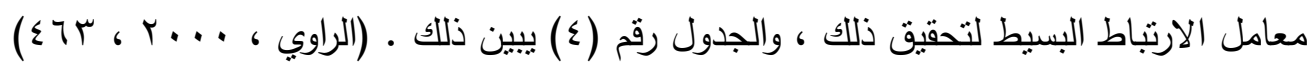

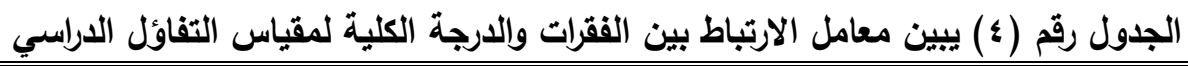

\begin{tabular}{|c|c|c|c|c|c|c|c|c|}
\hline دلالة الفروق & الارتباط معامل & رققم & دلالة الفروق & الارتباط معامل & رقام & دلالة الفروق & الارتباط معامل & رقة \\
\hline معنوي & $\cdot, \Delta \wedge r$ & .41 & معنوي & $\cdot, H \circ V$ & .1. & غير معنوي &., 170 & .1 \\
\hline معنوي & $\cdot, 499$ &.$Y Y$ & غير معنوي &., 111 & .11 & غير معنوي & $\cdot, \pm \leq 9$ &.$Y$ \\
\hline معنوي & $\cdot, Y q 1$ &.$Y \varepsilon$ & معنوي & $\cdot r \circ V$ & $.1 Y$ & معنوي & $\cdot, r \wedge r$ &.$r$ \\
\hline معنوي & $\cdot, v \cdot q$ &. Yo & معنوي & $\cdot, 0 \leq 7$ & .11 & معنوي &., $09 \mathrm{~V}$ &.$\varepsilon$ \\
\hline معنوي & $\cdot, 7 \leq \varepsilon$ & .47 & معنوي & $\cdot, r \leqslant Y$ & $.1 \varepsilon$ & معنوي & •, זY & .0 \\
\hline غير معنوي & $0,1 \leq 9$ & YV & معنوي & $\cdot, 7 \wedge r$ & .10 & معنوي &., $07 \varepsilon$ & .7 \\
\hline معنوي &., $71 \varepsilon$ & $r \wedge$ & معنوي & $\cdot, Y \cdot 1$ & .17 & معنوي &., 00 &.$V$ \\
\hline معنوي &., $19 V$ &.$\mu$ & معنوي & $\cdot, \leq \leq 0$ & .11 & معنوي &., 091 & .9 \\
\hline
\end{tabular}

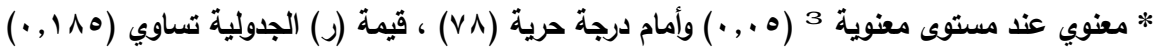

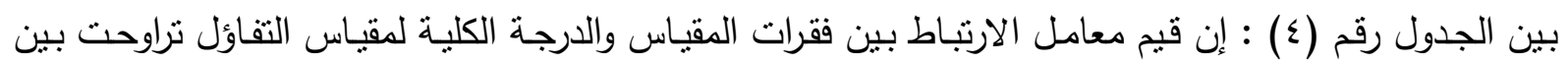

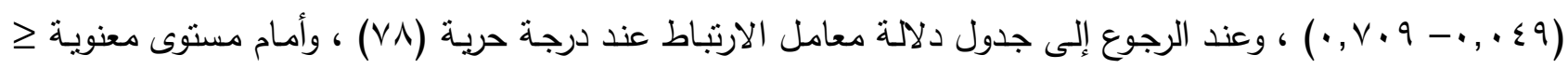

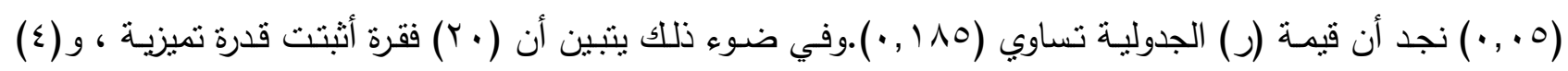

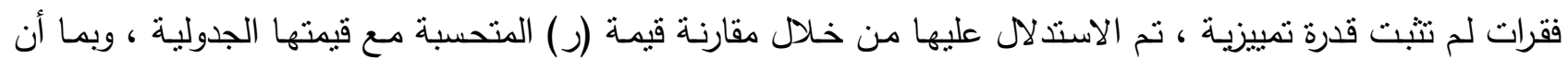
قيمة (ر) المحتسبة اقل من قيمة (ر) الجدولية ، فقد تم حذف الفقرات ضعيفة التمييز ، وبذلك فان عدد فقرات مقياس التفـاؤل غير المميزة والمحذوفـة هي (• (1) فقرات ، وبهذا يصبح مقياس التفاؤل بصورته النهائيـة بعد عملية التحليل

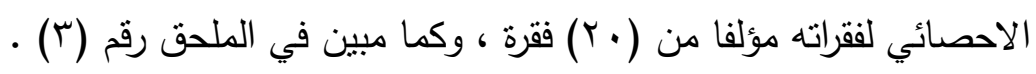
r-r-r ثبات المقياس : يثير الثبات إلى " الانسجام او الاتساق في النتائج " (Gronbach,1960,126) ، ولغرض الحصول على ثبات المقياس استخدمت طريقـة التجزئـة النصفية ، بأسلوب الفقرات (الفرديـة والزوجيـة) ، إذ تم تطبيق المقياس على عينة الثبات البالغ عددها (·r) طالب وطالبة، وتم تصحيح استماراتهم ثم قسمت إلى نصفين ، النصف الأول يمثل الفقرات ذات التسلسلات الفردية، والنصف الثاني يمثل الفقرات ذات النسلسلات الزوجية ، بحيث أصبح لكل فرد درجتان (فردية وزوجيـة)، وتم استخدام معامل الارتباط البسيط بين درجات نصفي المقياس، فظهرت قيمته تساوي (VV) , • )، " إن الارتباط بين درجات كل من نصفي الاختبار يعد بمثابـة الاتساق الداخلي لنصف الاختبار فقط وليس

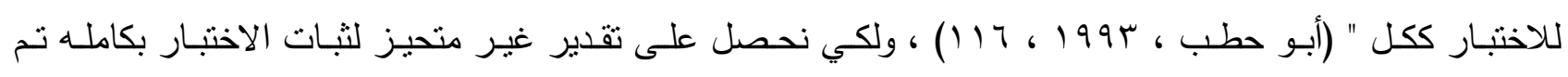
استخدام معادلـة (سبيرمان - براون) لتصحيح معامـل الثبات، اذ بلغت قيمـة معامـل الثبـات الكلي (NV , • )، وهـو دال إحصائيا مما يدل على ثبات المقياس .

r-r- §وصف المقياس وتصحيحه : مقياس التفاؤل لطلبة كلية التربية الرياضية في جامعة الموصل الملحق رقم (r) ، تألف المقياس بصورته النهائية من (·r) فقرة ، وتتن الاجابـة عن فقرات المقياس من خـلال خمسة بدائل هي (موفق

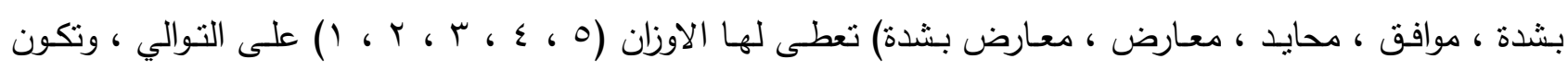

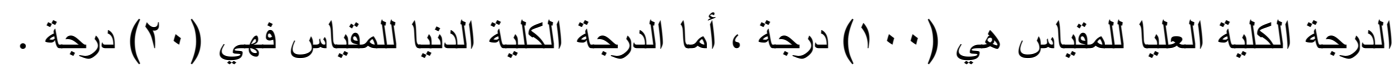




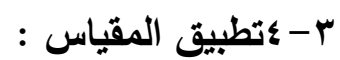

تم تطبيق المقياس على (·r ( ) طالب وطالبة ، واستبعد (·r) طالبا لعدم الحصول على استماراتهم ، وعدم

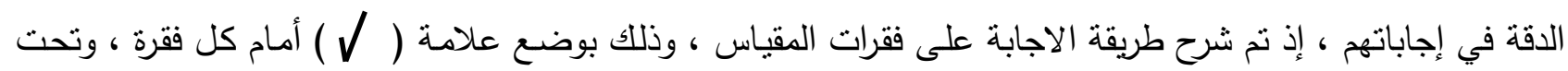
البديل الذي يراه مناسبا ، علما أن الاجابة تكون على كراسة المقياس نفسه ، ثم تم جمع كراسات المقياس من الطلبة ، وتم تصحيحها ، وبهذا تكون درجة المختبر على المقياس هي مجموع درجاته على فقرات المقياس جميعا . r- ب- الوسائل الإحصائية : - - - المتوسط الحسابي

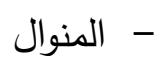

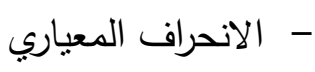

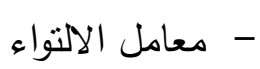
- معامل الارتباط البسيط

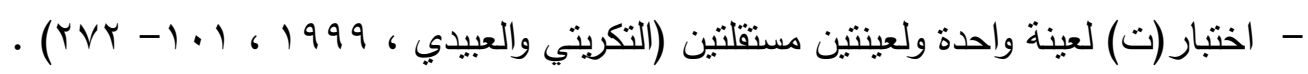

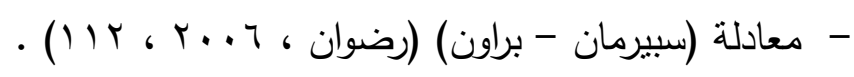

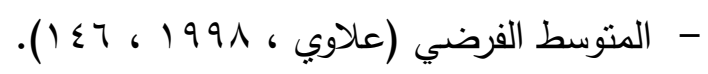

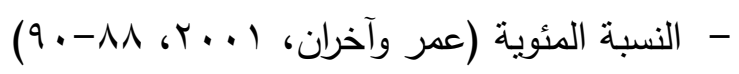

؛ -عرض وتحليل النتائج ومناقشتها :

؛ - اعرض نتائج عينة البحث في مقياس التفاؤل الدراسي :

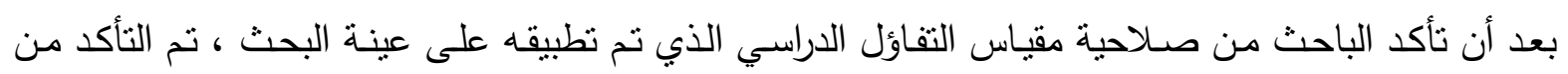
ملاءمة المقياس لعينة البحث عن طريق معادلة معامل الالتواء لـ(كارل بيرسون) ، ومنحنى التوزيع الطبيعي (ألاعتدالي)،

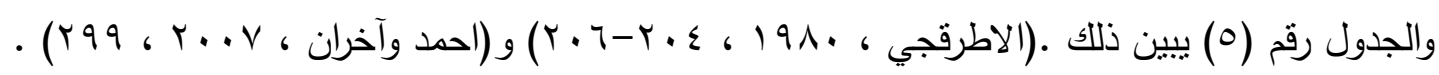
الجدول رقم (0) يبين المتوسط الحسابي والانحراف المعياري والمنوال ومعامل الالنواء لإجابات عينة البحث في مقياس

\begin{tabular}{|c|c|c|c|c|c|c|}
\hline النتيجة & الالتواء & المنوال & الانحراف & الحسابي & العينة & المعالم الاحصائية \\
\hline طبيعي * & $\cdot, \varepsilon$. & vo & $\wedge, \wedge \varepsilon$ & $V \wedge, 07$ & $1 \ldots$ & التفاؤل الدراسي \\
\hline
\end{tabular}

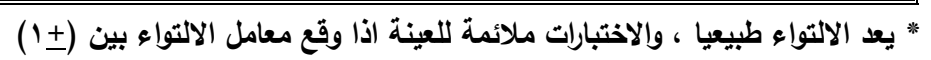

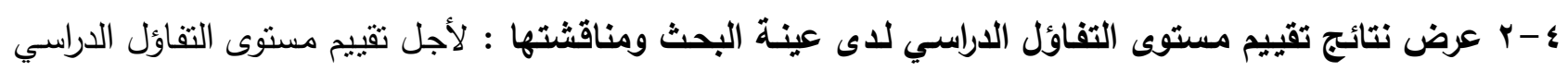
لدى عينـة البحث، قام الباحث بايجـاد المتوسط الفرضـي للمقياس، ومقارنته بدرجـة المتوسط الحسابي لديهه، وسـوف يصنف التفاؤل الدراسي الى تفاؤل عالي، وتفاؤل منخفض، على اساس ان متوسط العينة الذي يفوق المتوسط الفرضي للمقياس بصورة معنوية هو تفاؤل عالي، فيما تمثل القيمة غير المعنوية تقاؤل ضمن حدود المتوسط الفرضي، اما القيم

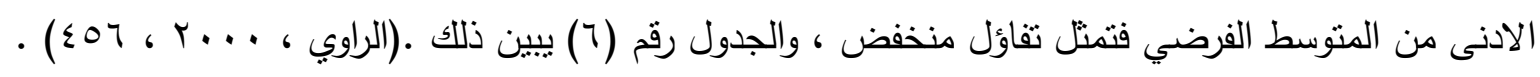
الجدول رقم (؟) بين المتوسط الحسابي والانحراف المعياري والمتوسط الفرضي وقيمة (ت) المحتسبة لعينة البحث في مقياس التفاؤل 


\section{بناء مقياس التفاول الدراسي الطابة كاية التربية الرياضية في جامعة المومل وعلاقته بالتمصيل الدراسي}

\begin{tabular}{|c|c|c|c|c|c|}
\hline قيمة (ت) & المتوسط & الانحراف & الحتوسط الحسبي & العينة & المعالم الإحصائية \\
\hline$* r \cdot, q$ & $* q$. & $\wedge, \wedge \leq$ & $\vee \wedge, 0 Y$ & $1 \ldots$ & التفاؤل \\
\hline
\end{tabular}

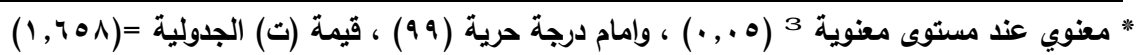

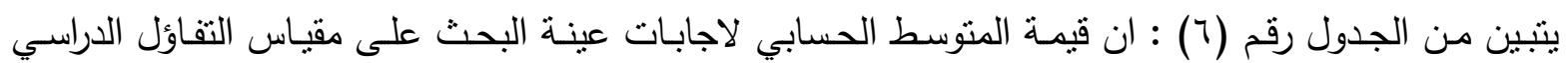

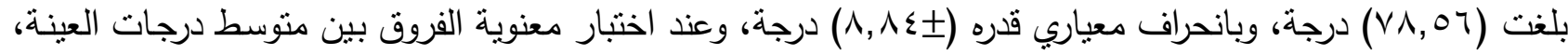

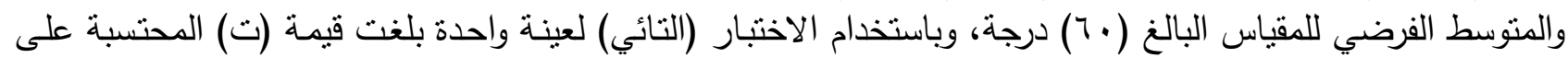

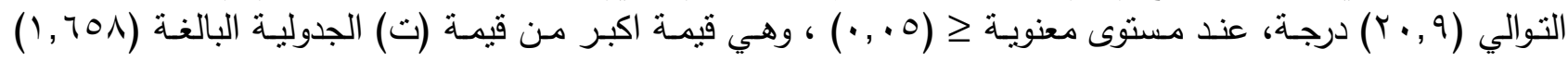

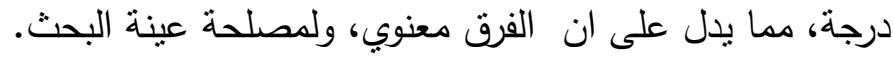
ومما سبق اظهرت النتائج ان طلبة كلية التربية الرياضية في جامعة اندة الموصل يتمتعون بمستوى تفاؤل دراسي اعلى من المتوسط الفرضي للمقياس، وهذا يدل على ان النتيجة ايجابية ، مما يؤدي الى تمتعهم بمستوى تفاؤل دراسي فئي

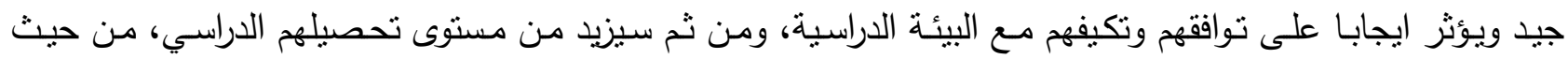

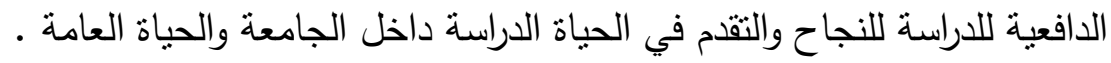

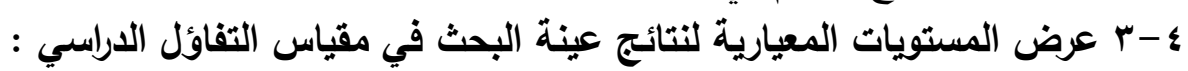

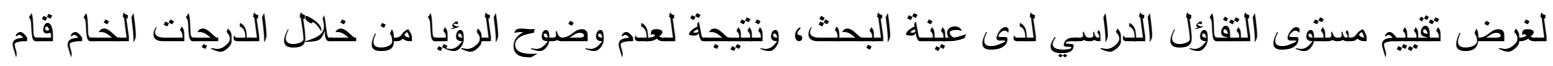

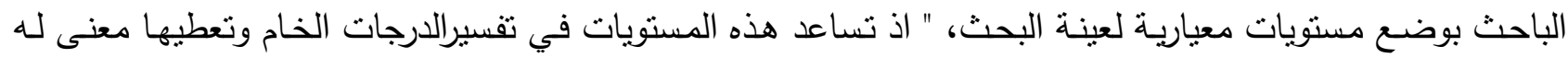

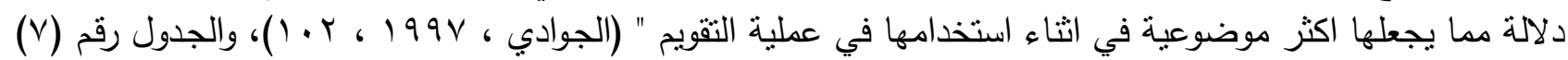
يبين ذلك. دلالة

\begin{tabular}{|c|c|c|c|}
\hline النسبة المئوية & عدد الطلبة & المستوى المعياري & الارجة الخام \\
\hline- & - & جيد جدا & G فاكثر \\
\hline$\% 19$ & 19 & جيد & $97-\wedge \Lambda$ \\
\hline$\%$ \%r & $r r$ & متوسط & $\Lambda V-V q$ \\
\hline$\% r r$ & r & مقبول & $V \wedge-V$. \\
\hline$\% \backslash r$ & ir & ضعيف & $79-71$ \\
\hline$\% \varepsilon$ & $\varepsilon$ & ضعيف جدا & . . فاقل \\
\hline$\% 1 \ldots$ & $1 \ldots$ & $\wedge, \wedge \varepsilon=\varepsilon \pm$ & س = \\
\hline
\end{tabular}

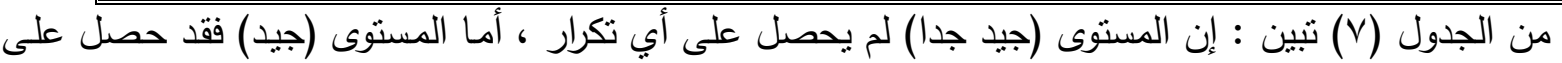

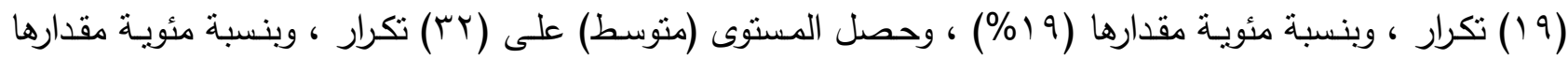

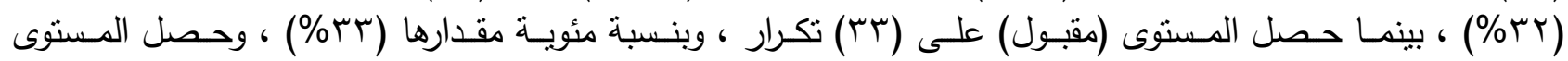

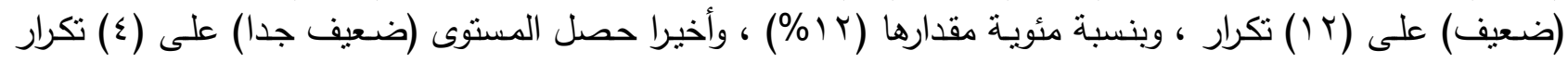

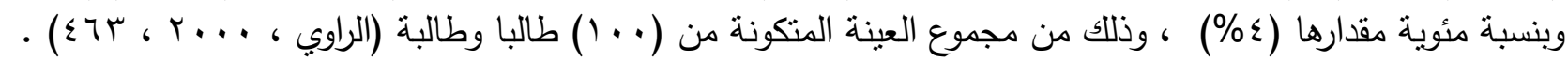

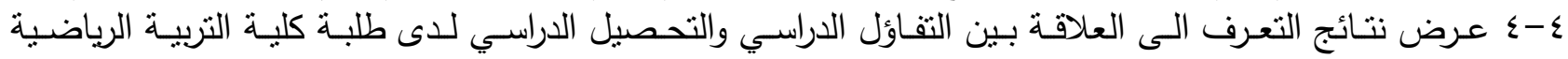
ومناقشتها:

الجدول رقم (^)يبين المتوسط الحسابي والانحراف المعياري ومعامل الارتباط بين مقياس التفاؤل الدراسي والتحصيل الدراسي لاى عينة البحث الارئ 


\begin{tabular}{|c|c|c|c|c|}
\hline قالمحتسبة (ر) & الانحراف & الحستوبط & العينة & المعالم الاحصائية \\
\hline \multirow{2}{*}{$*, \quad\{r q$} & $\Lambda, Y q$ & Vo & \multirow{2}{*}{ r. } & التفاؤل الدراسي \\
\hline & $\varepsilon, 19$ & $r^{\prime}, Y_{1}$ & & التحصيل الدراسي \\
\hline
\end{tabular}

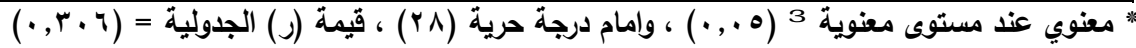

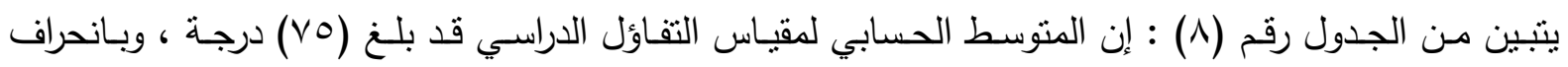

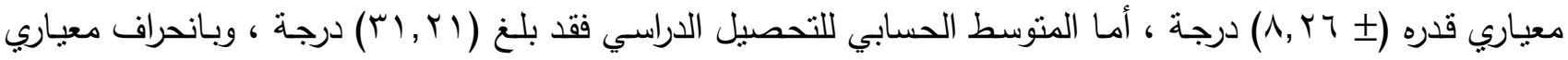

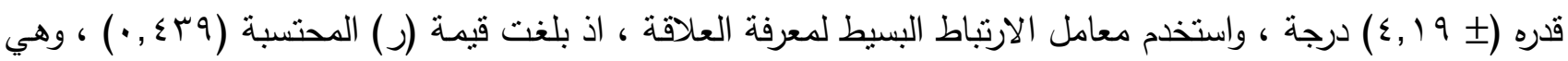

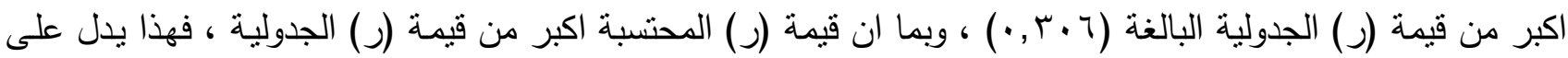

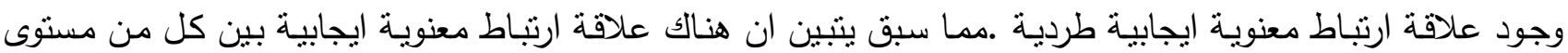
التفاؤل الدراسي والتحصبل الدراسي لدى طلبة كلية التربية الرياضية في جامعة الموصل . ويعزو الباحث هذه النتيجة إلى إن التفاؤل الدراسي يرتبط بنجاح الفرد ، فالروح الرياضية العالية لا تعرف ولانه

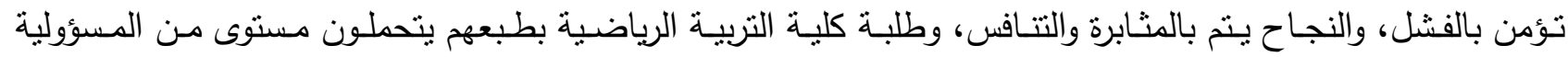

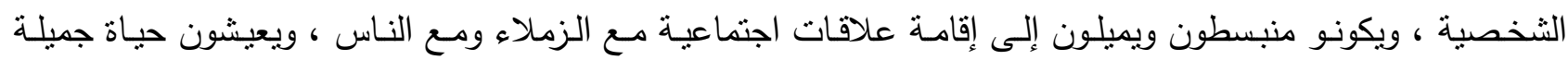
Scheiera \& Carver, ) ومزدهرة ، ومن ثم تؤثر إيجابا على صحتهم النفسية والبدنية والعقلية ، وهذا ما أكدته دراسته

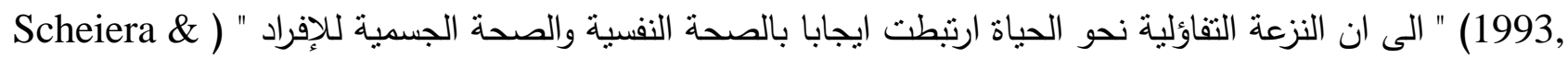

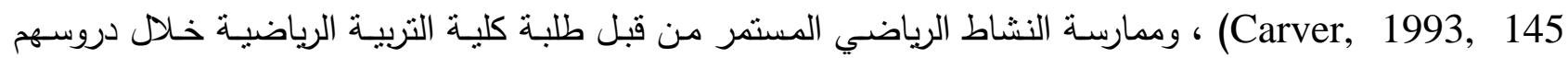

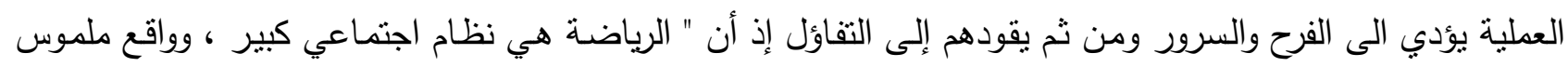
في حياتتا يحدث فيها كل أنماط السلوك التي تحدث في الحياة العادية ، فالرياضـة جزء من نسيج هذا المجتمع أي أنها

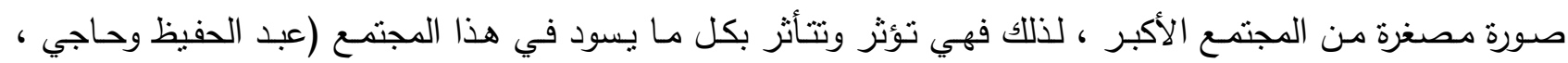

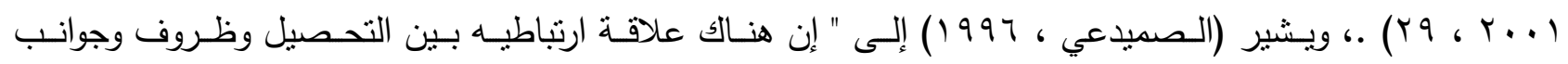
الاستعداد العقلي ، وبعض جوانب الشخصية ، والعوامل الأسرية ، والمدرسية ، وهناك باحثين آخرين قد أضافوا عوامل وله

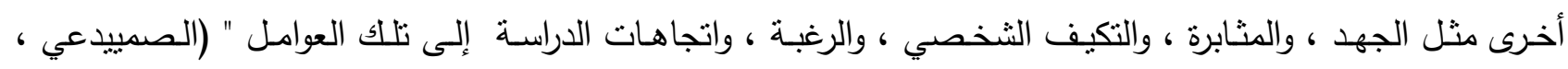

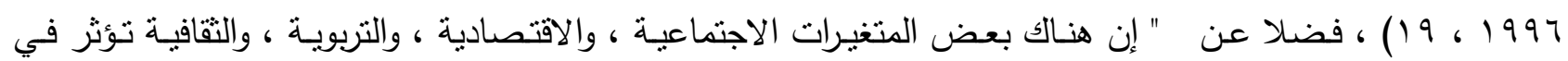
التحصيل بقدر أو بأخر مثل اتجاهات الوالدين ، وحجم العائلة ، والوضـع النفسي ، والاجتماعي ، والاقتصادي للطالب "

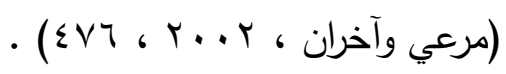

0- الاستنتاجات وإلتوصيات:

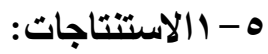

ه- - - فاعلية المقياس الذي نم بنائه لقياس مستوى التفاؤل الدراسي لطلبة كلية التربية الرياضية في جامعة الموصل

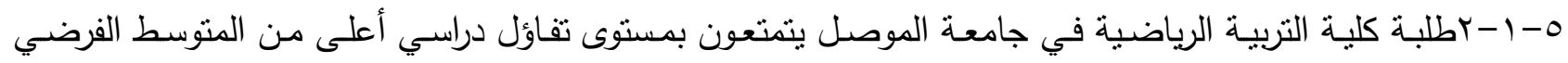

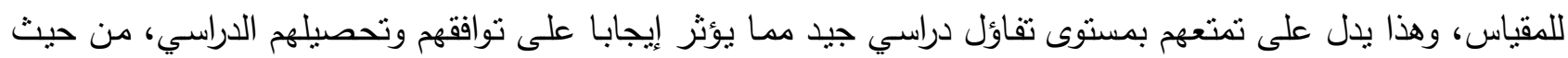

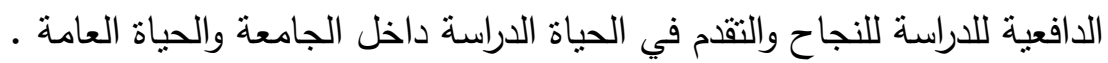

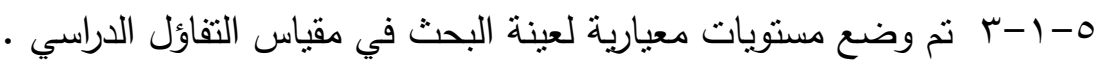
ه- ا-ـ وجود علاقة ارتباط معنوية ايجابية بين التفاؤل الدراسي والتحصيل الدراسي لدى طلبة كلية التربية الرياضية في جامعة الموصل . مجل 


\section{بناء مقياس التفاول الدراسي لطابة كلية التربية الرياضية في جامعة الموصل وعلاقته بالتصصيل الدراسي}

0 - مالتوصيات:

0- - اضرورة تبصير الإدارة الجامعية بالاهتمام بالطلبة، وإعدادهم نفسيا لتسهيل تكيفهم الدراسي ، والذي بدوره يؤثر

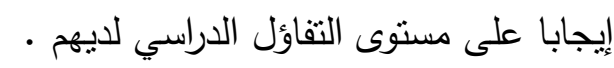

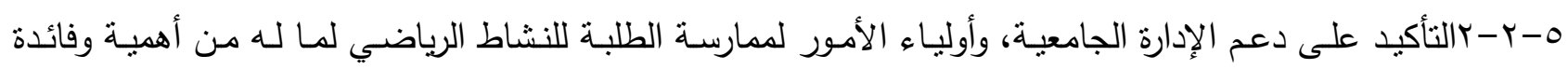

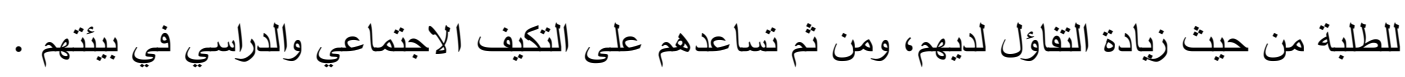
المصادر العربية والأجنبية:

أبو حطب ، وآخران (ب99 (1)) : التقويم النفسي ، طس ، مكتبة الانجلو المصرية ، القاهرة .

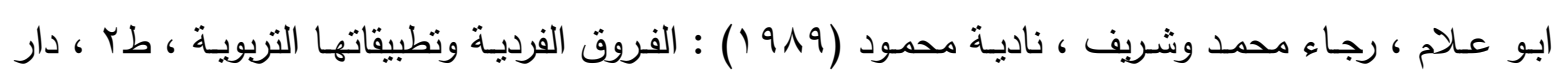

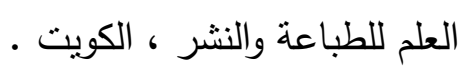

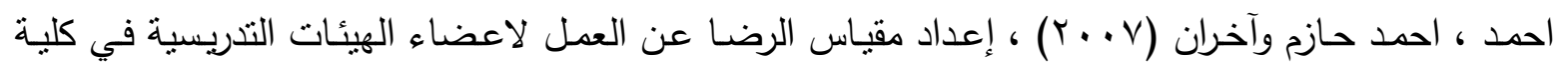
وأقسام التربية الرياضية في جامعة الموصل ، بحث منشور في مجلة أبحاث التربية الأساسية ، المجلد (V) ،

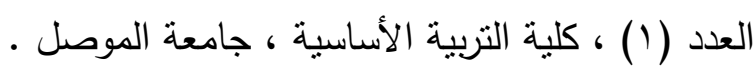

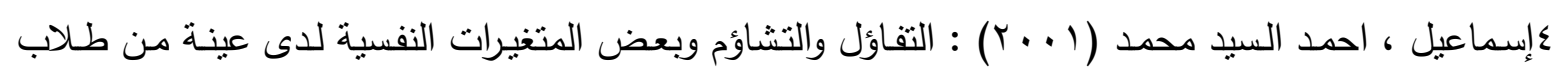
جامعة ام القرى ، بحث منشور في المجلة التربويـة ، المجلد (0 1) ، العدد ( • ب) ، كليـة التربية ، جامعـة ام القرى ، السعودية . الاطرقجي ، محمد علي (·919) : الوسـائل التطبيقيـة في الطرق الاحصائية ، طا ، دار الطليعـة للطباعـة والنشر ، بيروت.

الأنصاري ، بدر محمد (r . . r) : قياس التفاؤل والتشاؤم وعلاقتهما ببعض المتغيرات الشخصية لدى طلاب جامعة الكويت ، (المرجع في مقاييس الثخصية) ، بحث منشور في مجلة حوليـات ، كلية الاداب والعلوم الاجتماعية ، جامعة الكويت.

باهي ، مصطفى حسين (999 (19) : المعاملات العلمية بين النظرية والتطبيق ، مركز الكتاب للنشر ، مصر بلوم ، بنيامين واخرون (ب (9 1) : تقييم تعليم الطالب التجميعي والتكويني ، ترجمة محمد امين المفتي واخرون ، دار ماكرو هيل ، القاهرة.

التكريتي ، وديـع ياسين والعبيدي ، حسن محمد عبد (999 (19) : التطبيقـات الاحصائية في بحوث التربيـة

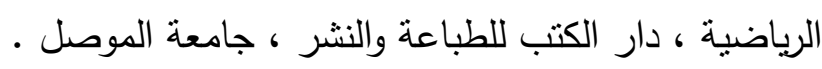
الجوادي ، عبد الكريم قاسم (997 (1)) : بنـاء بطاريـة اختبار المهارات الهجوميـة بكرة اليد لطـلاب كليـة التربيـة

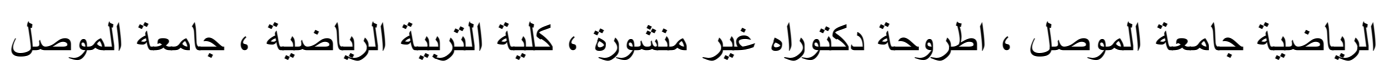

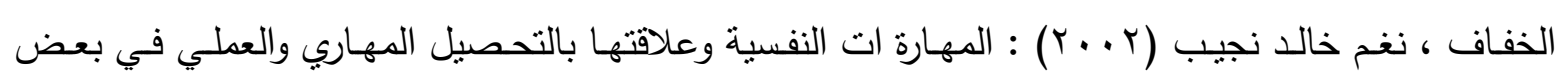
مهارات الكرة الطائرة ، رسالة ماجستير غير منشورة ، كلية التربية الرياضية ، جامعة الموصل .

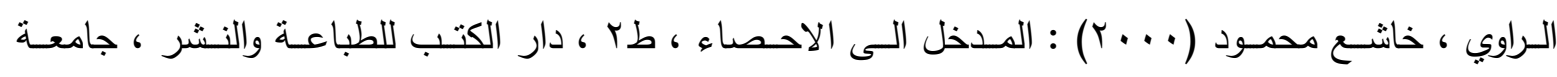
الموصل

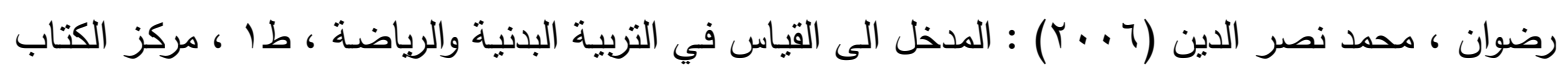
للنشر ، مصر ، القاهرة . 
الريب ، محمد مصطفى (ع . × ؟) : اساليب في التعلم التعاوني ، دار عالم الكتب للطباعة والنشر ، القاهرة . الصميدعي ن وضـاح غانم (797 (1) : اثر الاسلوب التبادلي في مستوى الاداء الفني والتحصيل في السباحة

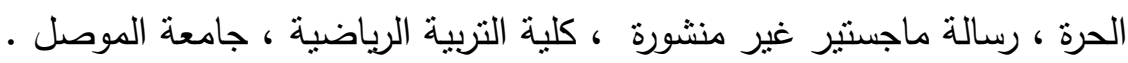
عبد الحفيظ ، اخلاص محمد وحاجي ، مصطفى حسين (1 . ب) : الاجتماع الرياضي ، طا ، مركز الكتاب للنشر والتوزيع ، القاهرة .

علاوي ، محمد حسن (99v (19) : مدخل علم النفس الرياضي ، طا ، دار المعارف للطباعة والنشر ، القاهرة علاوي ، محمد حسن (99199) : مدخل علم النفس الرياضي ، طب ، دار المعارف للطباعة والنشر ، القاهرة . عمر ، وآخران (1 + . ץ) : الاحصاء التعليمي في التربية البدنية والرياضية ، طץ ، دار الفكر العربي ، القاهرة

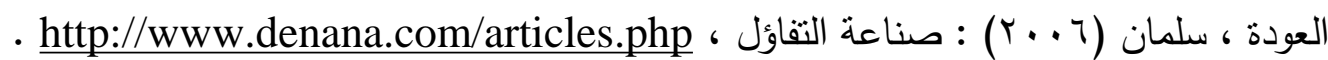
عويس ، خير الدين علي احمد (999 (19) : دليل البحث العلمي ، دار الفكر العربي للطباعة والنشر ، القاهرة كاظم ، علي مهدي ( •99 (19) : بناء مقياس مقنن لمفهوم الذات لدى طلبة المرحلة الاعدادية ، رسالة ماجستير غير منشورة ، كلية التربية الاولى ، جامعة بغداد . كـاظم ، علي مهدي (؟99 1) : بنـاء مقيـاس مقنن لسمات شخصية طلبـة المرحلـة الاعداديـة في العـراق ، اطروحة دكتوراه غير منشورة ، كلية التربية ابن رشد ، جامعة بغداد .

مرعي ، نوفيق احمد واخران (Y . . r) : تقربد التعليم ، دار الفكر للطباعة والنشر والتوزيع ، عمان

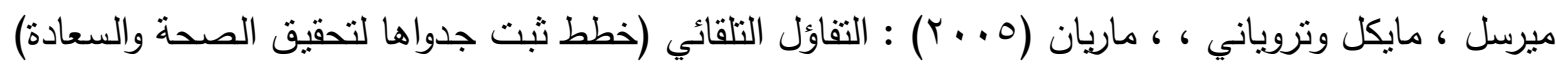

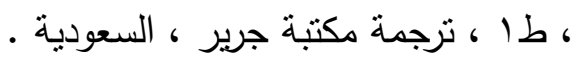

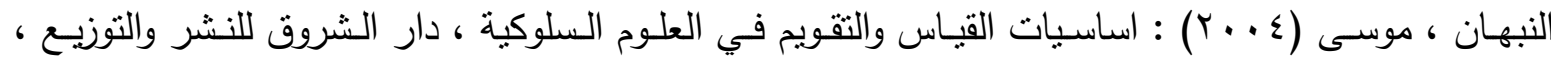

- Ahman J. Stanly and Marvin , cook (1971) : measuring Evaluating Educational achivement Allynard Bacon, Boston .

- Cronbach, L.J (1960) : Essentials of psychological testing Harper and row , publishers, New York .

- Scheie, M.F; \& Carver, C.S (1993) : On the power of positive thinking, the benefits of being optimistic psychological Seience, New Jersey .

- Schulz, R Brookhaven, J, Knapp, J.F, \& Scheier. M (1996) : Pessimism, Age, and Cancer survival, psychology \& Aging, New York.

بسم الله الرحمن الرحيم

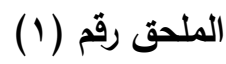

جامعة الموصل

كلية التربية الرياضية

يبين استنيان آراء السادة الخبراء حول صلاحية فقرات مقياس التقاؤل الدراسي

الأستاذ ................................................................................ 


\section{بناء مقياس التفاول الدراسي المبة كلية التربية الرياضية في جامعة الموصل وعلاقته بالتمصيل الدراسي}

يـروم الباحث إجراء البحث الموسـوم " بنـاء مقيـاس التفـاؤل الدراسـي لطلبـة كليـة التربيـة الرياضية في جامعـة الموصل وعلاقته بالتحصيل الدراسي " • ويقصد بالتفاؤل الدراسي : " نظرة استبشار نحو المستقبل تجعل الفرد يتوقع الافضل وينتظر حدوث الخير ويرنوا الى النجاح ويستبعد ما عدا ذلك ، او التوقع القصير المدى بالنجاح في تحقيق بعض المطالب في المستقبل " . ونظراً لمـا تتمتعون بـه من خبرة ودرايـة علميـة في بناء المقاييس ، وفي مجال العلوم التربويـة والنفسية ومجال القياس والتقويم ، فقد تم اختياركم كاحد الخبراء للحكم على مدى صـلاحية الفقرات المرفقة طيا ، والتي تم صباغتها من خلال ، الت الاطلاع على المصادر العلمية ، وبعض الدراسات والمقاييس السابقة الخاصـة بالموضوع قيد البحث ، راجين تقضلكم بقراءة الاستبيان والاجابة على ما يأتي : - وضع علامة ( ) امام كل/فقرة ، وتحت البديل الذي تراه مناسباً للفقرة ( تصلح ، لا تصلح ، تصلح بعد التعديل من خلال (حذف او اعادة صياغة او اضافة عدد من الفقرات) . - مدى صلاحية الإجابة على فقرات المقياس ضمن سلم التقدير (خماسي التدرج) ، على طريقة (ليكرت) ، وفق (0) بدائل هي (كثيرا جدا ، كثيرا ، متوسط ، قليلا ، لا) ، وتعطى لها الأوزان ( 0 ، ؛ ، ب ، ب ، 1 ) على التوالى لفقرات تصلح

واذا لم تحصل الموافقة فما هو السلم البديل برأيكم ؟ شاكرين تعاونكم العلمي المبارك

المقياس التوقيع: اللقب العلمي: الباحث الاختصاص: م.م. علي حسين محمد طبيل الجامعة والكلية :

\begin{tabular}{|c|c|c|c|c|}
\hline تصلح بعد التعديل & لاتصلح & تصلح & الفقرات & $\ddot{ت}$ \\
\hline & & & |درك ان دراستي تؤمن لي مكانة اجتماعية جيدة & .1 \\
\hline & & & مرموقا ان تخصصي الاراسي سيساعدني في المستقبل على شغل منصبا &.$r$ \\
\hline & & & اجمل لحظات حياتي ستكون عندما اتخرج من الكلية &.$r$ \\
\hline & & & ممارستي للنشاط الرياضي يساعدني على التفاؤل بالحياة &.$\varepsilon$ \\
\hline & & & اشعر ان امالي التي لم تتحقق اليوم سوف تتحقق مستقبلا & .0 \\
\hline & & & ارغب في التفوق على زملائي في دروسي & .9 \\
\hline & & & |نظر الى المستقبل على انه سيكون سعيدا &.$v$ \\
\hline & & & دراستي تشعرني بالرضا والاطمئنان على مستقبلي &.$\wedge$ \\
\hline & & & احب المشاركة ضمن الفرق الرياضية في الكلية & .9 \\
\hline & & & |رغب باكمال دراستي (العليا) بعد التخرج & .1. \\
\hline & & & | وجودي في كليتي مـع زملائي يشعزني بالسعادة & .11 \\
\hline
\end{tabular}




\begin{tabular}{|c|c|c|c|c|}
\hline & & & دروسي (النظرية والعملية) تؤئر ايجابا على حياتي & .14 \\
\hline & & & روحي الرياضية العالية تجطني اتظلب على اكثر المشاكل & .14 \\
\hline & & & الشعر ان المستقبل سيكون مشرقا وسعيدا & $.1 \leqslant$ \\
\hline & & & لاي ثقة كبيرة في نجاحي & .10 \\
\hline & & & ارى ان ممارستي للانشطة الرياضية تمنحني الثقة بالنفس & .14 \\
\hline & & & اعتقد ان كل امر صعب عبارة عن سحابة لا تستمر طويلا & $.1 \mathrm{~V}$ \\
\hline & & & وارئلية اختصاصي الدراسـي يساعدني على تحقيق الصحة البانيـة & .11 \\
\hline & & & علاقتي الايجابية مع اساتنتي تساعدني في اجتياز العقبات & .19 \\
\hline & & & لدائما افكر في الامور السعيدة والمفرحة &.$r$. \\
\hline & & & اشعر ان فرص النجاح موجودة دائما من اجل تقدمي في الدراسة & .4 \\
\hline & & & التفاؤل سمة تلازمني في حياتي & .rY \\
\hline & & & الشعر بالمشاعر الطيبة تجاه زملائي الطلبة &. $\mathrm{rr}$ \\
\hline & & & أؤدي واجباتي الدراسية بحرص وسرور & . r \\
\hline & & & اتوقع ان يمنحني تفوقي الدراسي مفاجات سارة في المستقبل & . ro \\
\hline & & & استمتع بحضور الندوات والمهرجانات الرياضية &. $\mathrm{T4}$ \\
\hline & & & انا مقبل على الحياة بحب وتفاؤل &. $\mathrm{TV}$ \\
\hline & & & ارى ان دراستي جعلت لي الحياة جميلة &. $\mathrm{.r \Lambda}$ \\
\hline & & & تمنحني دراستي القدرة على حل المشكلات التي تواجهني بسهولة & 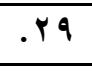 \\
\hline & & & اتفاءل بالمستقبل من خلال دراستي &.$r$. \\
\hline & & & اشعر ان لامكان لليأس في اثناء دراستي &.$\mu 1$ \\
\hline & & & اتوقع نتائج جيدة في تحصيلي الدراسي (النظري والععلي) & .rr \\
\hline & & & اتعامل مع الضغوط الدراسية بحكمة وتعقل & . \\
\hline & & & يكسبني المنهج الدراسي المعرفة الجيدة في المستقبل & $. \mu \leqslant$ \\
\hline & & & غالبا ما اتوقع نتائجا ايجابية في المستقبل &.$\mu_{0}$ \\
\hline
\end{tabular}

الملدق رقم (ץ) : يبن مقياس التفاؤل الدراسي بصورته الاولية

\begin{tabular}{|c|c|c|c|c|c|c|}
\hline بثدارة & 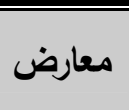 & محايد & 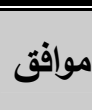 & بموافق & 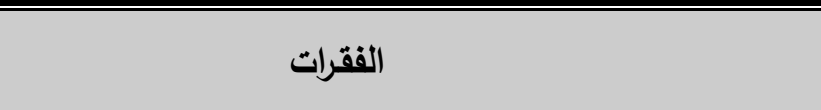 & 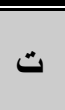 \\
\hline & & & & & ادرك ان دراستي تؤمن لي مكانة اجتماعية جيدة & .1 \\
\hline & & & & & ارى ان تخصصي الدراسي يضمن لي منصبا مرموقا & r \\
\hline & & & & & اجمل لحظات حياتي ستكون عندما اتخرج من الكلية &.$r$ \\
\hline & & & & & ممارستي للنثاط الرياضي يمنحني التفاؤل بالحياة & $\varepsilon$ \\
\hline & & & & & اشعر ان امالي سوف تتحقق مستقبلا & .0 \\
\hline & & & & & ارغب في التفوق على زملائي في دروسي & .1 \\
\hline & & & & & اشعر بالفوز عند المشاركة ضمن الفرق الرياضية في الكلية &.$v$ \\
\hline & & & & & ارغب باكمال دراستي (العليا) بعد التخرج & .1 \\
\hline & & & & & وجودي في كليتي يشعرني بالسعادة & .9 \\
\hline
\end{tabular}




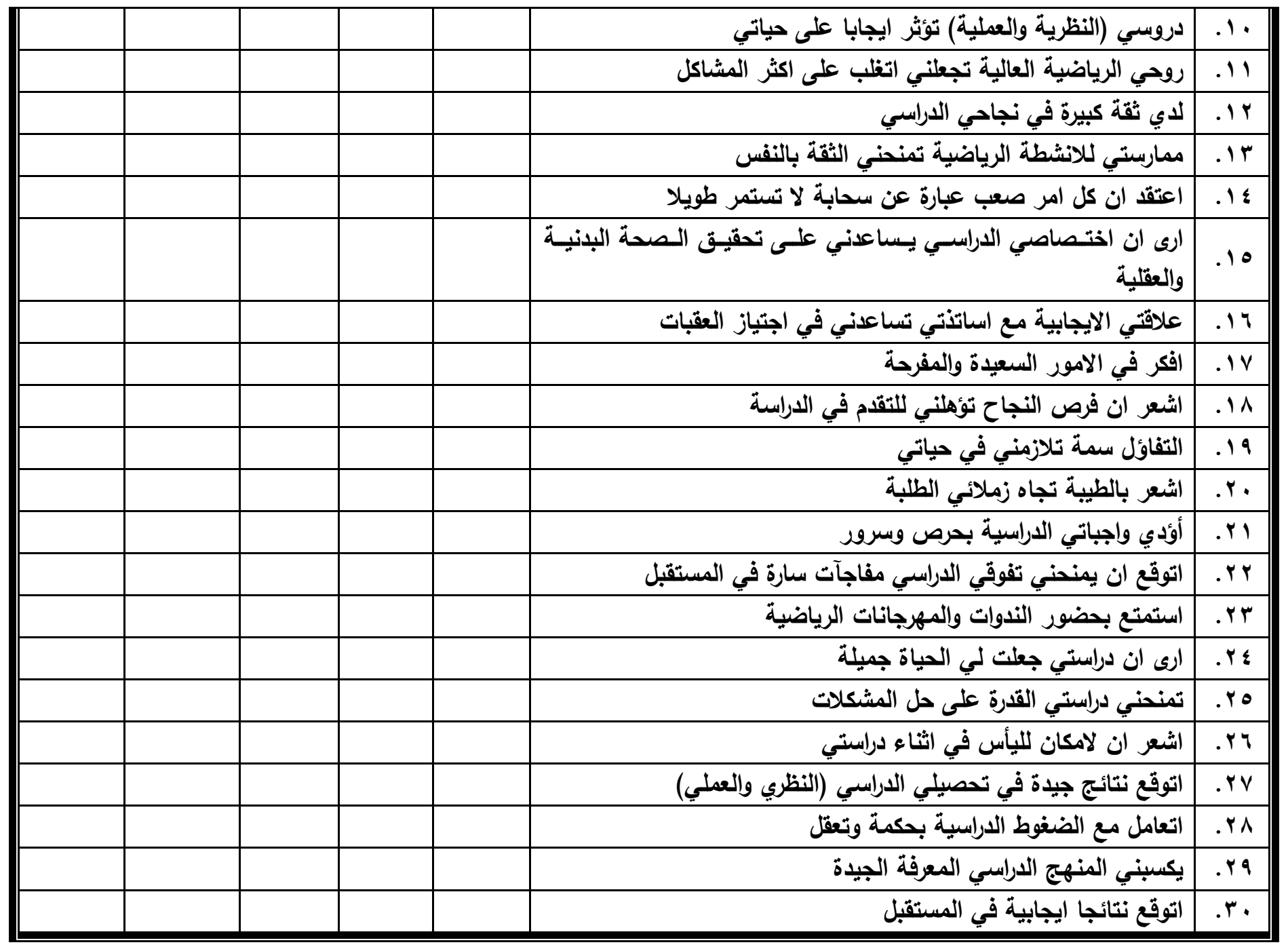

الملدق رقم (r) يبين مقياس التفاؤل الدراسي بصورته النهائية

\begin{tabular}{|c|c|c|c|c|c|c|}
\hline بثعارة & 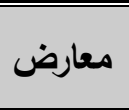 & محايد & 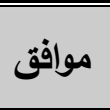 & بشدافق & الفقرات & 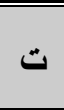 \\
\hline & & & & & اجمل لحظات حياتي ستكون عندما اتخرج من الكلية & .1 \\
\hline & & & & & ممارستي للنشاط الرياضي يمنحني التفاؤل بالحياة &.$r$ \\
\hline & & & & & اشعر ان امالي سوف تتحقق مستقبلا &.$r$ \\
\hline & & & & & ارغب في التفوق على زملائي في دروسي & . \\
\hline & & & & & اشعر بالفوز عند المشاركة ضمن الفرق الرياضية في الكلية & .0 \\
\hline & & & & & وجودي في كليتي يثعرني بالسعادة & .7 \\
\hline & & & & & دروسي (النظرية والعملية) تؤُثر ايجابا على حياتي &.$v$ \\
\hline
\end{tabular}


بناء مقياس التفاول الدراسي الطبة كلية التربية الرياضية في جامعة الموصل وعلاقته بالتمصيل الدراسي

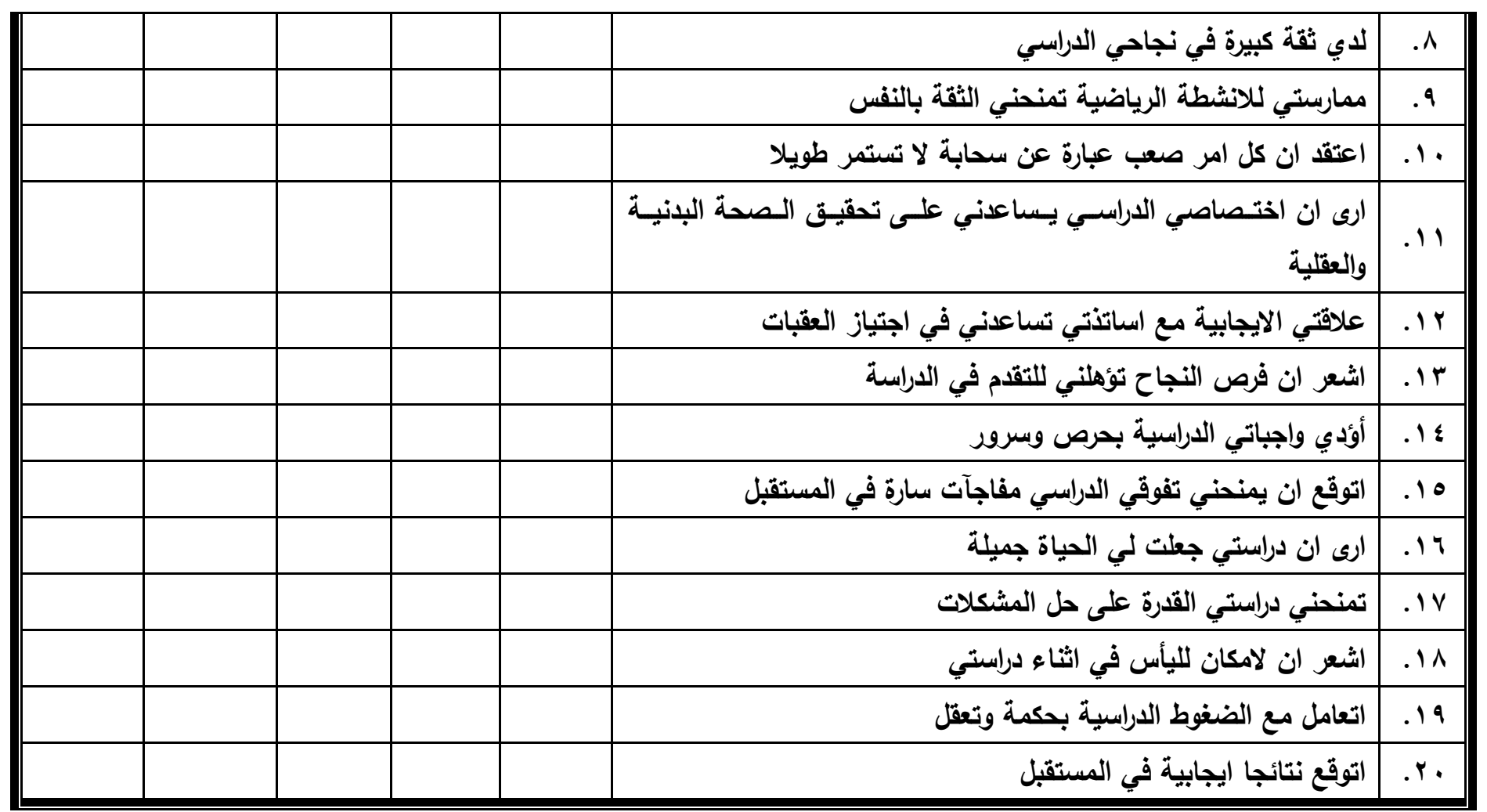

